\title{
PROPUESTAS DE REDUCCIÓN DEL TIEMPO DE TRABAJO EN GIPUZKOA ${ }^{1}$
}

\author{
Verónica Castrillón Serna \\ Jose Mari Zendoia SaInZ \\ Jon Bernat Zubiri Rey \\ Departamento de Economía Aplicada I \\ Euskal Herriko Unibertsitatea / Universidad del País Vasco (UPV/EHU)
}

DOI: 10.1387/lan-harremanak.16568

\section{ABSTRACT}

Desde el inicio de la recesión se está padeciendo un incremento sostenido del paro de larga duración y del subempleo. En este artículo se estudian politicas de reducción del tiempo de trabajo (RTT) aplicables al caso de Gipuzkoa como vía para reducir el desempleo, abordando cuestiones territoriales, socio-laborales y productivas. Analizamos diferentes propuestas en las que se ha evaluado en qué medida la RTT puede tener efectos positivos de una traslación del tiempo liberado a nuevos puestos de trabajo, asi como sus efectos redistributivos en diferentes escenarios de financiación y por sectores productivos. Se ha dado especial importancia a la compensación salarial, siendo nuestra posición partidaria de una RTT sustancial y equitativa, tanto en la creación de puestos de trabajo como en su financiación.

Palabras clave: desempleo, reparto del tiempo de trabajo (RTT), distribución de la renta, fiscalidad, Gipuzkoa.

${ }^{1}$ La autoría de este artículo está indicada por orden alfabético, justificada en el trabajo equitativamente compartido de análisis del reparto del tiempo de trabajo, en el marco del Proyecto de Investigación «Reparto del empleo y del tiempo de trabajo: efectos en la fiscalidad y tratamiento jurídico», financiado por el Departamento de Innovación de la Diputación Foral de Gipuzkoa, a ejecutar entre el 22-12-2014 y el 30-10-2015. 
Since the beginning of the recession, there has been a sustained increase in longterm unemployment and in underemployment. In this article policies of working time reduction (WTR) as a way to reduce unemployment are studied, applicable to the case of Gipuzkoa, addressing territorial, social, labour and productive issues. We analyse different proposals which evaluate to what extent the WTR can have positive effects by producing a translation of freed up time into new jobs, as well as its redistributive effects on different funding scenarios and by productive sectors. Special importance has been given to salary and wage compensation, since our position supports a substantial and equitable WTR, both in job creation and in its funding.

Keywords: unemployment, working time reduction (WTR), income distribution, tax system, Gipuzkoa

Atzeraldi ekonomikoa hasi zenetik epe luzeko langabeziak eta azpienpleguak etengabeko gorakada izan dute. Artikulu honetan langabezia gutxitzeko Gipuzkoan bideragarriak izan daitezkeen lanaldiaren murrizketa (LM) politikak aztertzen dira, lurralde arazoak, soziolaboralak eta produktiboak kontutan hartuz. Proposamen desberdinak lantzen ditugu, horietan ebaluatuz LMk lanpostu berrien sorreran izan ditzakeen ondorio positiboak, hala nola birbanatze efektuak, finantziazio-eszenario desberdinetan eta sektoreka. Garrantzi berezia eman zaio soldata-konpentsazioari, gure hautua funtsezko eta bidezko LM izanik, bai lanpostuen sorreran, baita bere finantziazioan.

Hitz gakoak: langabezia, lanaldiaren murrizketa, errentaren banaketa, fiskalitatea, Gipuzkoa 


\section{Introducción}

En este artículo se analiza la viabilidad de la puesta en marcha de políticas de reducción del tiempo de trabajo (RTT) en Gipuzkoa como instrumento clave con el que hacer frente a la cronificación del desempleo y al subempleo. El trabajo se organiza en tres secciones.

En el segundo apartado se plantean los principales elementos de diagnóstico del problema que se quiere resolver: el desempleo de larga duración y la proliferación del sub-empleo. Hemos atendido al sesgo estructural por sexos y generaciones, así como a la importancia de plantearse esta cuestión desde el marco laboral y normativo del territorio, cerrando con una serie de cuestiones técnicas para proyectar la incidencia de la RTT sobre cuestiones productivas y de potencial efecto de creación de nuevos empleos.

En el tercer apartado se propone una RTT sobre el total de la población ocupada (incluyendo asalariados y autónomos), para reducir la tasa de desempleo al 5\% en dos escenarios. En el primero, con una reducción homogénea de la jornada, y en el segundo contemplando la creación de puestos de trabajo a jornada parcial. En este último caso no sería muy difícil compensar a los trabajadores a tiempo parcial con algún tipo de prestación la parcialidad de su jornada laboral.

Por último, en el cuarto apartado, se analiza una RTT dirigida exclusivamente al empleo asalariado de Gipuzkoa, que representa en torno a un $87 \%$ de la población ocupada. Para reducir la tasa de desempleo al 5\%, planteamos una reducción homogénea de la jornada que se compense con creación de puestos de trabajo a tiempo completo y se evalúa el efecto redistributivo de esta medida en diferentes escenarios de financiación y por sectores productivos.

Las propuestas que pasamos a desarrollar requerirían, para su implantación, un estudio más pormenorizado y preciso del entramado productivo y socio laboral gipuzkoano (marco laboral, tipología empresarial, de la población desempleada, condiciones de la población ocupada, fiscalidad, etc.). Se trata pues de un primer análisis que nos permita establecer una metodología de trabajo y obtener unos resultados globales que sirvan de orientación general para, con el objetivo de reducir drásticamente la tasa de paro, determinar qué jornada laboral 
habría que implantar y evaluar los efectos redistributivos que podrían desencadenarse.

\section{Algunas consideraciones sobre la RTT para reducir el desempleo y la parcialidad forzada}

\subsection{Diagnóstico de los problemas desde el territorio}

La RTT, el viejo Lavorare meno per lavorare tutti, constituye una línea de intervención política de aplicación general y es por tanto al Estado español a quien compete en primera instancia intervenir en la materia, pero a nuestro juicio resultaría una medida viable y de gran potencialidad para la mejora de los datos del empleo y la distribución de la renta en la economía gipuzkoana.

Cuando la Diputación de Gipuzkoa decidió lanzar un conjunto de investigaciones sobre el reparto del empleo, una de las primeras reflexiones que abordamos en nuestras reuniones fue la de los márgenes de intervención territoriales, y lo hicimos atendiendo a las particularidades normativas de entornos como el de Gipuzkoa o Navarra, pero sin dejar de considerar otros ámbitos de aplicación posibles. En Bengoetxea (2016) se argumenta la viabilidad de su aplicación en Gipuzkoa frente a quienes sostienen que «todas las competencias están en manos del Estado"; además de la propia ejemplaridad que deben ejercer las Administraciones Públicas vascas en su política de personal y contrataciones, existen posibilidades de coordinación y compensación entre diferentes administraciones que tienen competencias ligadas al empleo, el paro y la fiscalidad ${ }^{2}$. Es posible asimismo adoptar medidas en este sentido dentro de los marcos normativos forales vascos y, más concretamente, de la Diputación Foral de Gipuzkoa, que ha financiado este estudio ${ }^{3}$.

La RTT es además una política socio laboral de primer rango para hacer frente al desempleo y la inactivación - mayormente de hombres con experiencia y edad avanzada y de muchos y muchas jóvenes con poca o caótica proyección laboral- y al auge del subempleo y de la creciente especialización en sectores de alta precariedad y parcialidad forzada, con rostro principalmente femenino (Zubiri, 2014).

${ }^{2}$ Un ejemplo de estas posibilidades de cooperación inter-institucional viene de la pista de trabajo en común con un Gobierno de Navarra que en su Acuerdo programático recoge la voluntad de profundizar en la vía de la RTT

${ }^{3}$ Empezando por la fiscalidad y las medidas de incentivo a la RTT. Habría que ver que complementariedades y márgenes regulatorios y normativos se dan o se pueden crear, y en qué condiciones, y pensando en quién financia la RTT y abordando el debate sobre su reparto y posible compensación. 
Del análisis de las evoluciones sectoriales (Castrillón et al., 2016a; 2016b; 2016c) se observa que las oportunidades de empleo continúan cayendo hasta el tercer trimestre de 2015 (de la Fuente y Zubiri, 2016). La pérdida en Bizkaia, Gipuzkoa y Araba de 60.000 empleados en la industria y 32.000 en la construcción — de 2008-III a 2014-III (Eustat, 2015) — hacen necesaria una apuesta de cambio de modelo productivo en el medio y largo plazo (Gadrey et al., 2013) y una política de RTT en el corto plazo, más bien con urgencia, dados los problemas laborales y sociales que la cronificación del desempleo origina.

ELA (2015a) contabiliza con datos del SEPE a 31 de agosto de 2015 la existencia de 129.000 parados de larga duración en Hego Euskal Herria, siendo estables en la CAPV y reduciéndose en varios miles en Navarra. Igualmente, la misma fuente constata que, respecto al conjunto de personas desempleadas contabilizadas - no inactivas, desanimadas, o exiliadas-, el 55\% recibió una prestación contributiva o subsidio en julio de 2013, contra un 45\% en julio de 2015.

En lo que se refiere al aumento del empleo a tiempo parcial, de la Fuente y Zubiri (2016), han analizado los datos que muestran que el empleo a jornada completa en la CAPV — temporal o indefinido- pierde 52.000 efectivos desde el final del $2011 \mathrm{al}$ final del 2014. El empleo a tiempo parcial —en gran parte femenino- aumenta en casi 9.000 efectivos durante el mismo periodo, pasando así del 20\% al 22,7\% de las personas afiliadas al Régimen General de la Seguridad Social (CES, 2015). Por último, en cuanto a los nuevos contratos, casi el $39 \%$ de todos los firmados en la CAPV entre enero y mayo del 2015 fueron a tiempo parcial (ELA, 2015b). El empleo a tiempo parcial forzado tiene efectos negativos $y$, junto a los contratos temporales, constituye un supuesto de baja calidad del empleo especialmente femenino, más en un contexto de fuertes caídas de la ocupación de los hombres como las observadas en las relaciones laborales vascas y gipuzkoanas.

Conviene tener esto en consideración al plantear políticas de reducción del tiempo de trabajo que contemplen la creación de empleo a tiempo parcial voluntario. Esta opción forma parte de una de las dos proyecciones de reparto del empleo efectuadas en la siguiente sección. El actual estado de la cuestión muestra que, lejos de esta hipótesis, la creciente involuntariedad de los empleos a tiempo parcial sube en toda Europa y con mucha más virulencia en los países de la periferia europea - los GIPSI- y, por ejemplo en España, esta involuntariedad pasa del 36\% en 2008 al 62\% en 2013 (ETUI, 2015: 30). Parece evidente que, en defecto de un empleo a jornada completa, cada vez más trabajadoras aceptan jornadas parciales que, como decíamos, se conjugan con formas flexibles de organización del trabajo. Además, estos empleos refuerzan la división sexual del trabajo existente, relegando a las mujeres a las esferas más invisibles y peor valoradas de la actividad social, tanto remunerada como no remunerada (Carrasco, 1995). 
Este diagnóstico nos permite afirmar que la vía de RTT que se aplica actualmente es generadora de dualidad socio laboral. Una parte de la clase trabajadora sufre una creciente acumulación de trabajo que incluye multitud de horas extras no remuneradas (Durán, 2015). El 35\% de las personas que hacía horas extras en 2008 en España no recibían a cambio ninguna remuneración, frente al 58\% que hacen horas extras en esta injusta condición en 2015 (De la Fuente y Zubiri, 2016a). Aún así, tanto el volumen total como el porcentaje de personas asalariadas que hacen horas extras, ha disminuido, siendo en 2015 el $4 \%$ de la clase asalariada (UGT, 2015): menos personas que trabajan más tiempo y la mayoría en peores condiciones, especialmente las mujeres, los jóvenes y los inmigrantes.

La otra cara de este proceso de dualización se encuentra en las personas que resultan cada vez más excluidas o precarizadas, en situaciones de desempleo o sub-empleo. Algo que ya apuntaba Bertrand Russell (1932) al considerar que el paro estructural de las economías capitalistas contrasta con la negación de "tiempo libre para la vida" de todas las personas, relegando a unas que quisieran trabajar a tener un "exceso" de tiempo libre y a muchas, que de serles posible trabajarían menos horas, a no poder atender debidamente otras cuestiones importantes en sus vidas.

A resolver esta dualidad se dedican las políticas de reparto de los aumentos de productividad generados por las economías europeas en las últimas décadas, mal repartidos por la no compensación vía aumentos de salario y RTT permanentes. Porque «históricamente la RTT ha sido considerada como una remuneración en especie de las mejoras de productividad que se iban alcanzando gracias a los avances técnicos y económicos» (Alonso y Pérez, 1996: 73). Siendo esta cuestión compleja, y en general mal entendida, pasamos a comentar algunos aspectos relativos a los efectos de las políticas de RTT en la producción y el empleo.

\subsection{Teniendo en cuenta las principales cuestiones sociolaborales y productivas}

Para el análisis de cuestiones socio-laborales y productivas de carácter técnico, haremos uso de las reflexiones del libro ¿Trabajo para todos?: un debate necesario (Alonso y Pérez, 1996), donde se dedica una parte importante a abordar las cuestiones relacionadas con la productividad, los salarios y la utilización de los equipos productivos. También consideran los autores la influencia de la RTT sobre los comportamientos de actividad y las «diferentes maneras en que los distintos sectores e incluso ramas de actividad pueden absorber la reducción de la jornada» (57), dándose efectos de retardo entre la implantación de la RTT y las nuevas contrataciones, ya que las empresas tenderán a intentar minimizarlas en espera de observar la incidencia del cambio normativo (58).

Igualmente, sobre las condiciones de la creación de empleo, remarcan la importancia de prever y anticipar que la RTT (75-76) produce el afloramiento de 
ganancias pasivas y eventuales reducciones del absentismo derivados de la reducción de la fatiga. $\mathrm{Si}$, tal y como proponemos, la reducción es además sustancial, también puede reducir las bajas por enfermedad y los accidentes laborales. Estos efectos "podrían incrementarse si la empresa introdujera ciertas medidas que permitiesen a los trabajadores una mayor autonomía en la gestión de su actividad y de su tiempo dentro y fuera del lugar de trabajo» (horarios flexibles, descansos compensatorios, etc.). Si a esto se suma la reducción de porosidades (tiempos de inactividad en cada hora y jornada laboral) y la posible mejora en la gestión de las pausas, ya se apuntan múltiples vías de adaptación de los procesos productivos previas a las nuevas contrataciones.

Además, en caso de aplicación de una política de RTT, podría ocurrir que las medidas que permitan una organización más flexible del trabajo "se presentaran como la contrapartida que las empresas deseaban ante las reivindicaciones de reducción de jornadas de los trabajadores» (79). "Lo importante es que las nuevas modalidades de organización del trabajo no supongan, en ningún caso, un empeoramiento de las condiciones del mismo" (80).

De la misma forma que en la organización de la producción, la otra cuestión clave de toda RTT negociada colectivamente se encuentra en la «compensación salarial». Es decir, en cómo se financian los aumentos en los —al menos iniciales- incrementos en los costes laborales horarios. Si su carga no puede cargarse exclusivamente a las empresas, se requieren diseños de aplicación generales bien planeados y que sopesen la incidencia demográfica de las condiciones y supuestos a aplicar. En muchos casos hará falta también planteamientos sectorializados de implantación de la RTT, acordes a la participación relativa del trabajo en los procesos productivos y a las relaciones de producción en cada uno de los mismos. La «compensación total» implica el mantenimiento del salario total tras una RTT. En su vertiente de "compensación parcial» las nuevas horas libres sólo dejan de pagarse en parte, «registrándose en consecuencia un aumento de las ganancias por hora y una disminución de los salarios por persona; y ello siempre en menor proporción que el tiempo reducido. Este tipo de compensación se justifica por los aumentos de productividad consecutivos a la RTT» (81). Riechmann y Recio (1997: 49) argumentan que una RTT «sin compensación» —es decir, con reducción proporcional de salario - no debería ser considerada una política de reparto del trabajo, sino más bien de reparto del paro, o de «solidaridad dentro de una sola clase» (31). Consideran, por contra, que la compensación parcial —reducción del salario total, aumento del salario hora- puede aceptarse siempre que «no empeore la distribución global de rentas en detrimento de los trabajadores y que no disminuyan los salarios más bajos» $(57)^{4}$.

\footnotetext{
${ }^{4}$ Ver en De la Fuente y Zubiri (2016b) un análisis sobre la experiencia francesa de RTT y los mecanismos de compensación salarial en la Ley Aubry II del 2000.
} 
Por último, Alonso y Pérez (1996: 89) analizan la complementariedad entre puestos de trabajo y equipos productivos. Consideran central de cara a una RTT la comprensión del carácter complementario de introducir «importantes reorganizaciones del trabajo, sin dejar de recurrir a nuevas inversiones» (97) que mitiguen los «múltiples factores que, a su vez, se interponen entre la reducción del tiempo de trabajo y la creación de empleo» (113).

Así mismo, apuntan que la «reordenación del tiempo de trabajo debe dar lugar a medidas del tipo RTT, prohibición de horas extraordinarias, o el reparto entre más trabajadores de los puestos de trabajo disponibles» (113). También consideran buenas las fórmulas salariales del tipo segundo cheque (Aznar, 1997), fundamentadas en la "compensación por vía pública» de la disminución salarial proveniente de la reducción del tiempo de trabajo mercantil. Este segundo ingreso compensatorio — simulado para Gipuzkoa en la siguiente sección - sería para estos autores «financiado por la vía de los impuestos sobre el uso de la maquinaria, el incremento de la productividad, el uso de recursos naturales no renovables o la imposición directa sobre los consumos más ostentosos» (113).

Todo lo expuesto busca reflexionar sobre los aspectos que den solidez al diseño de políticas de RTT. Como hemos argumentado, las políticas de RTT no deben considerarse como «el fruto de una serie de ajustes, debates y tendencias sociales cristalizadas a medio plazo" (114) ni tampoco deben tomarse como una medida coyuntural contra el desempleo, «tienen que adquirir el carácter de un tipo de planteamiento social mucho más profundo, de evaluación personal de las satisfacciones derivadas del trabajo y de valoración pública de los contenidos del trabajo» (Alonso y Pérez, 1996 : 115) y del tiempo libre.

En este camino, es indispensable empezar por los cimientos: diagnosticar el problema y empezar a cuantificar la potencialidad de una solución por la RTT. En este sentido, conviene tener en cuenta experiencias anteriores como el paso a las $35 \mathrm{~h}$ en Francia en donde se crearon entre $1 / 3$ y un 1/5 de los empleos que habrían resultado de la asignación del total de horas liberadas a nuevos puestos de trabajo a tiempo completo. Esta constatación es muy útil de cara a entender en perspectiva los resultados de las simulaciones que abordaremos en las secciones siguientes, según las cuales, una aplicación generalizada de las 35 horas en Gipuzkoa vendría a liberar una cantidad de horas de trabajo como para crear unos 25.000 nuevos empleos a tiempo completo. La superación de la franja de incidencia en el caso francés requeriría un análisis de las dificultades y obstáculos observados en su implantación para un diseño adecuado de los incentivos, compromisos y otras medidas más o menos coercitivas o de supervisión que posibiliten la máxima creación de empleo. 


\section{Dos escenarios para el conjunto de la población ocupada}

En las páginas siguientes realizamos un análisis para estudiar la posibilidad de repartir las horas trabajadas entre la población activa con el fin de reducir la tasa de paro hasta un 5\% que podríamos considerar como paro friccional. Para ello vamos a considerar en primer lugar las variables que condicionan el reparto del tiempo de trabajo y empleo en Gipuzkoa: número de puestos de trabajo equivalentes a tiempo completo (PTETC), la jornada laboral media anual, el número total de horas trabajadas, el ratio entre contratos a tiempo completo y contratos a tiempo parcial, y finalmente, el número de personas activas (trabajando o buscando empleo).

Basándonos en estos datos podemos intuir cómo habría que repartir el total de horas trabajadas entre las personas que trabajan o que quieren trabajar, de forma que se redujese la tasa de paro hasta un nivel considerado friccional, debido a que los ajustes en las relaciones laborales no se producen de forma inmediata.

Los dos escenarios que presentamos son situaciones que consideramos a modo de hipótesis de trabajo, en las que se señala cómo quedaría hipotéticamente el empleo final después de una reordenación y reparto de las horas trabajadas. Se tiene en cuenta a todas las población ocupada (asalariados en empresas privadas y en el sector público, cooperativistas y autónomos) y, más que una línea de acción, muestra los resultados posibles después de implementar políticas contundentes de reparto de empleo.

\subsection{Número de puestos de trabajo equivalentes a tiempo completo}

Figura 1

Número de puestos de trabajo equivalentes a tiempo completo

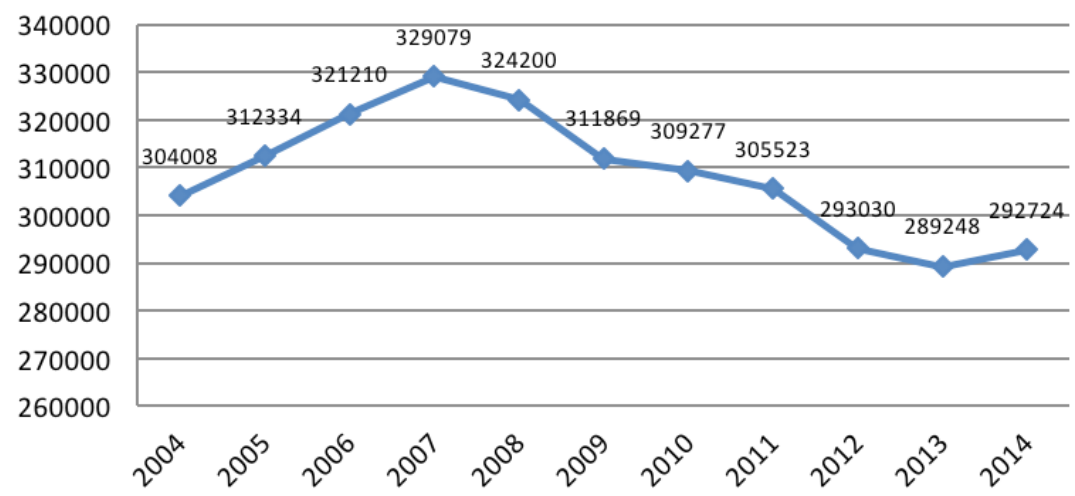

Fuente: Eustat. 
El número de puestos ETC ha disminuido desde 2007 hasta 2013, con una leve recuperación en 2014, quedando el último trimestre de ese año en 292.724 .

\subsection{Jornada laboral media (horas por año)}

La jornada media de un puesto equivalente a tiempo completo (asalariados y autónomos) se ha reducido en los últimos años hasta las 1.718 horas de media en 2012. Para ańos posteriores no existen datos disponibles, pero parece oportuno, dada la evolución de la variable, tomar como dato para 2014 una jornada media anual de 1.700 horas.

Figura 2

Jornada laboral media (horas por año)

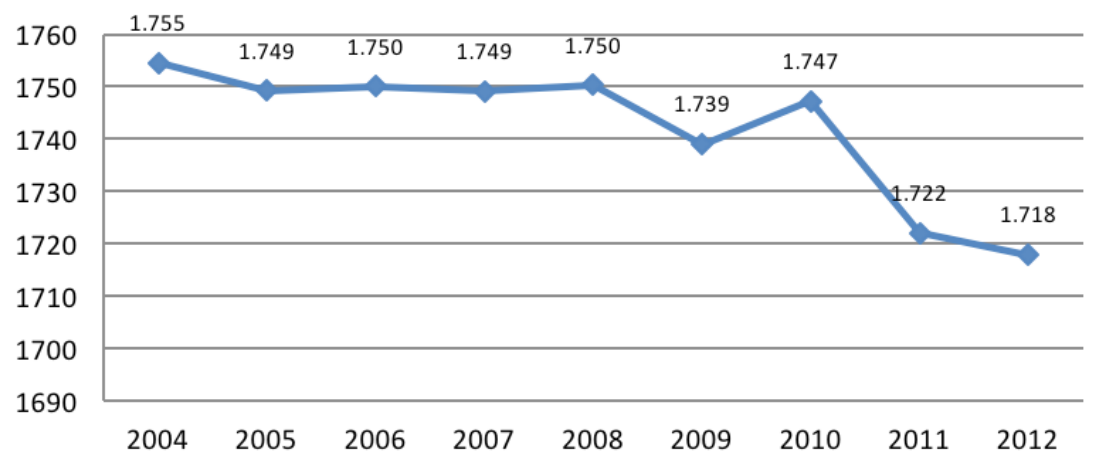

Fuente: Eustat.

\subsection{Número total de horas trabajadas}

Hasta el año 2007 el número de horas trabajadas en Gipuzkoa fue en aumento, pero a partir de dicho ańo ha disminuido. Si consideramos: a) que en los años 2013 y 2014 el número de ocupados se mantiene con respecto a 2012, pero teniendo en cuenta que muchos de los nuevos contratos son a tiempo parcial, y b) que la productividad total ha seguido aumentando en estos años, podemos intuir que el número de horas trabajadas en 2014 es menor que en 2012. Utilizando una regresión lineal para los años de la crisis, a partir de 2007, se obtiene que el número de horas trabajadas en 2014 es de 490 millones. Al corregir la tendencia, teniendo en cuenta la variación de puestos de trabajo ETC de los años 2013 y 2014 y la jornada media anual estimada para este último año, el número total de horas trabajadas en 2014 oscila entre 500 y 505 millones. 
Figura 3

Número total de horas trabajadas

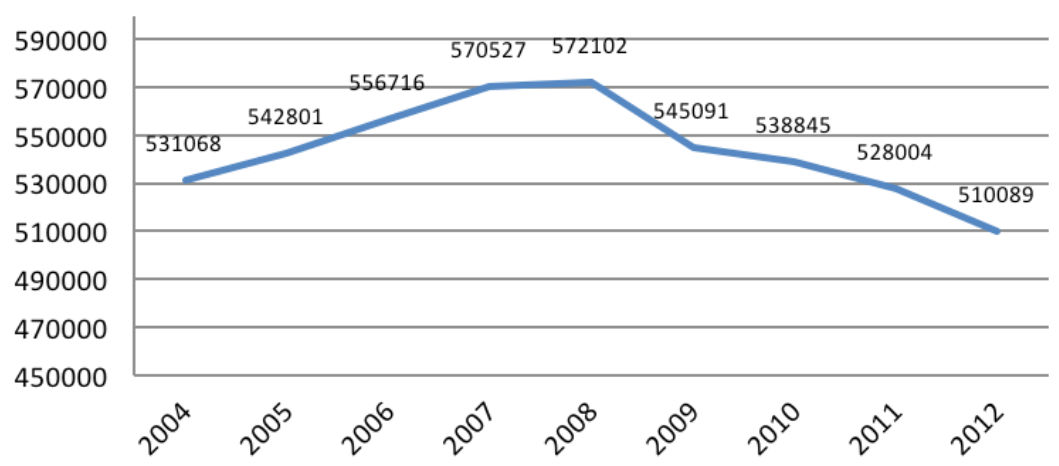

Fuente: Eustat.

\subsection{Proporción de trabajadores a JP/JC}

Las fuentes consultadas ofrecen diferentes resultados para la proporción de trabajadores con contratos de jornada parcial en Gipuzkoa. Así, para 2014 y según el SEPE, tomando únicamente como referencia a los asalariados, y tras ponderar el dato de los contratos en los que no consta el tipo de jornada, el 23\% de los asalariados trabaja a jornada parcial. Según los datos de Eustat, en 2014 esta proporción se encuentra en torno al 19\% para el conjunto de las personas ocupadas. Finalmente, según la Encuesta de Población Activa del INE, el porcentaje de ocupados a jornada parcial en la CAV es del 17\% en 2014.

Figura 4

Proporción de trabajadores a jornada parcial

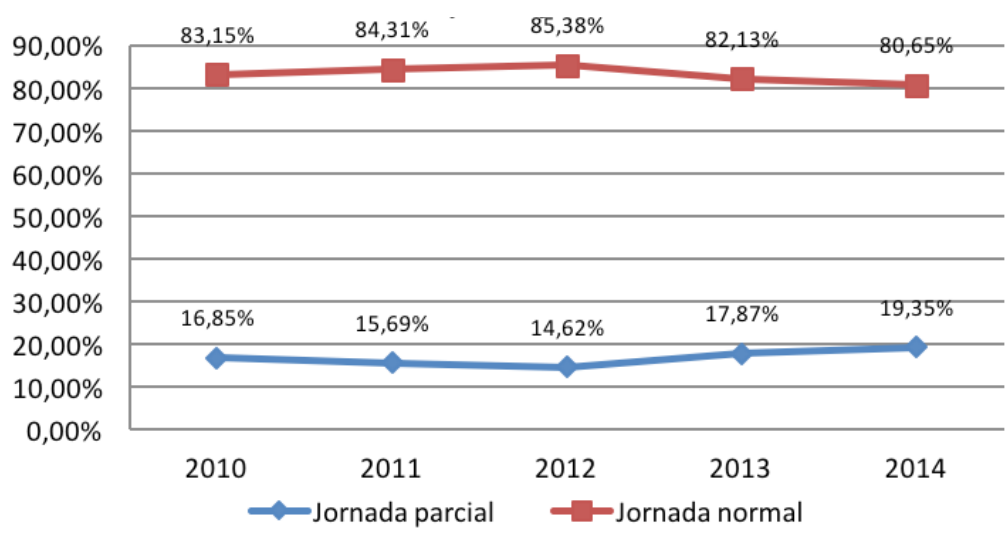

Fuente: Eustat. 


\subsection{Subempleo, tasa de trabajadores a JP que querrían trabajar a JC}

No hay datos disponibles para la CAV ni para Gipuzkoa, pero según informes de Eurostat para los diferentes países de la Unión Europea, en el estado español un 57\% de los trabajadores con jornada parcial desearían trabajar a tiempo completo (lo que a su vez supone en torno a un $10 \%$ de los trabajadores).

Figura 5

Número de personas activas (ocupados + parados)

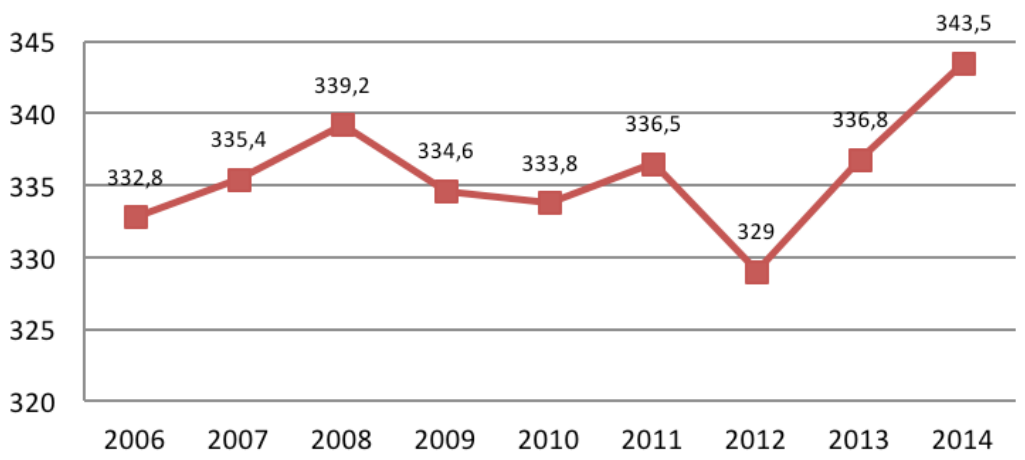

Fuente: Eustat.

El número de personas activas (trabajando o en busca de trabajo) tuvo un pico en el año 2008, se redujo en los siguientes años hasta las 329.000 personas en 2012 y ha aumentado hasta valores mayores a los previos al inicio de la crisis, con un total de 343.500 personas en 2014.

\subsection{Posible reparto del tiempo de trabajo}

Basándonos en los datos señalados en los puntos anteriores, vamos a estudiar a continuación qué tipo de jornada laboral habría que establecer en Gipuzkoa para reducir el actual nivel de desempleo que alcanza un 12,49\%. Partimos de la última situación conocida disponible (tabla 1).

Tomamos como base la hipótesis de que la tasa de paro friccional es del 5\%, es decir, que en el mejor de los casos, 5 de cada 100 trabajadores está sin empleo por distintas causas: jóvenes que se incorporan al empleo, personas en busca de otra ocupación, cambios de empresa, tiempo de espera entre la finalización de un contrato y el inicio de otro, etc. Esto significa que, con los datos de 2014, para un total de 343.500 personas activas, asumimos la existencia de 17.175 parados (el 5\% de los activos), con lo que quedan 326.325 personas trabajando. 
Tabla 1

Situación preliminar (promedio anual del año 2014)

\begin{tabular}{lc}
\hline Población activa & 343.500 \\
Ocupados & 300.500 \\
Parados & 42.900 \\
Tasa de paro & $12,49 \%$ \\
Puestos equiv. TC & 272.724 \\
Jornada media anual (horas, estimada) & 1.708 \\
Número de horas trabajadas (estimado) & 500.000 .000 \\
\hline
\end{tabular}

Fuente: Eustat.

Así reduciríamos el número de parados, de los 42.900 de promedio en 2014 (Eustat) a los citados 17.175, incorporando por tanto casi 26.000 parados al colectivo de personas ocupadas.

\subsubsection{Opción A}

En primer lugar, vamos a considerar que el número total de horas trabajadas por la población ocupada (incluyendo asalariados y autónomos), se cubren de forma homogénea por toda la población activa es decir, que todos los trabajadores tienen la misma jornada laboral anual. En este caso, para cubrir los $500 \mathrm{mi}-$ llones de horas que se trabajaron en 2014, cada una de las 326.325 personas ocupadas tendría que realizar anualmente un total de 1.532 horas, lo que viene a ser un $89,7 \%$ de la jornada media anual actual. O visto de otra manera, en lugar de una jornada semanal de 40 horas habría que realizar jornadas laborales de 35,8 horas.

Tabla 2

Opción A

\begin{tabular}{lc}
\hline Población activa & 343.500 \\
Ocupados & 326.325 \\
Parados & 17.175 \\
Tasa de paro & $5,00 \%$ \\
Nuevos empleos & 25.725 \\
Nueva jornada media anual & 1.532 \\
Nueva jornada / Jornada actual & $89,70 \%$ \\
Número de horas trabajadas & 500.000 .000 \\
Horas semanales & 35,88 \\
\hline
\end{tabular}

Fuente: elaboración propia a partir de datos de Eustat. 
En este caso, los trabajadores que actualmente tienen una jornada completa pasarían a trabajar menos horas a la semana, horas que serían cubiertas por los trabajadores que se encuentran en paro.

Consideramos que esta opción es la más difícil de llevar a la práctica en el corto plazo, porque supondría contratar a 25.725 nuevos trabajadores a tiempo completo: si se reducen los salarios en la misma proporción que la jornada laboral, no se está repartiendo el empleo si no que se reparte el paro (Riechman y Recio, 1997: 31), si se mantiene los salarios actuales las empresas verían elevados los costes salariales en más de 1.000 millones de euros para contratar el mismo número de horas trabajadas.

\subsubsection{Opción B}

Otra opción sería que una parte de los 326.325 trabajadores ocupados mantuviera la jornada completa actual (JC) media, de 1.718 horas anuales, y otra parte tuviera contratos a jornada parcial. Por simplificar, vamos a suponer que existen contratos con jornadas de tres cuartas partes de la jornada completa (JP75), y contratos a media jornada (JP50).

En este caso, una posible distribución sería la siguiente: el 70\% de los trabajadores a JC, el 20\% a JP/\%, y el 10\% restante a JP50. En este caso se llegarían a cubrir 504 millones de horas al año, con un 30\% de los trabajadores con contratos a jornada parcial. Hemos señalado previamente que en la situación actual los trabajadores a tiempo parcial están en torno al 20\% de los ocupados (según las fuentes), y que de estos, una parte considerable (la mitad, para el caso español) desearían trabajar a tiempo completo. Para la opción que estamos considerando, quedaría un 30\% de los ocupados trabajando a tiempo parcial, de los que una gran parte preferiría una contrato a jornada completa.

¿Cuánto cuesta esta actuación? ¿Cómo se financia? Consideramos que a los 17.175 parados (el 5\% de paro friccional aludido) habría que seguir abonándoles una renta de desempleo, que según datos de Eustat, el año 2012 se elevaba a $12.338 €$ anuales por parado registrado, con un gasto total en desempleo por parte de todas las administraciones de 562,6 millones de euros (en 2012, último año con datos disponibles).

Para los trabajadores con jornadas parciales, y basándonos en una idea de Aznar (1994) proponemos que perciban una compensación por la parte de la jornada que no trabajan, es decir, consideramos que los trabajadores con una jornada JP75 tienen a su vez una cuarta parte de jornada de parado, mientras que aquellos con una jornada JP50, son considerados como "medio" parados. Por lo tanto, al 20\% de los trabajadores activos con JP75 habría que compensarles con una cuarta parte del subsidio medio de desempleo, y al 10\% de activos con JP50 les correspondería la mitad de dicho subsidio. De esta forma un 
trabajador con JP75 recibiría una renta salarial equivalente al 83,5\% del salario correspondiente a JC, y un trabajador con JP50 llegaría al 67\% del salario del trabajador a JC.

Así, contando con 65.265 trabajadores JP75 y 32.633 trabajadores JP50, además de los 17.715 parados, resulta un gasto por desempleo más compensación de jornada parcial de 614,5 millones de euros.

Anteriormente se ha señalado que el gasto total por desempleo en 2012 alcanzó los 562,6 millones de euros, con lo que harían falta 52 millones de euros adicionales para poder repartir los diferentes tipos de jornada de forma que se cubran el número total de horas a trabajar. Esta opción resulta por tanto mucho más realizable que la reducción de jornada laboral sin reducción de salario: los 52 millones de euros necesarios para su implementación se obtendrían con creces de incrementos en la recaudación vía IRPF (121 millones a un tipo medio del $24 \%$, tomando en cuenta el incremento de renta de los nuevos empleados = salario neto - rentas por desempleo).

Tabla 3

Opción B

\begin{tabular}{|c|c|c|c|}
\hline Población activa & 343.500 & & \\
\hline Ocupados & 326.325 & & \\
\hline Trabajadores JC & 228.428 & & \\
\hline Trabajadores JP75 & 65.265 & & \\
\hline Trabajadores JP50 & 32.633 & & \\
\hline Parados & 17.175 & & \\
\hline Tasa de paro & $5,00 \%$ & & \\
\hline Nuevos empleos & 25.725 & & \\
\hline Número de horas anuales & 501.654 .289 & & \\
\hline \multicolumn{4}{|l|}{ Coste } \\
\hline X Gasto en desempleo ( $5 \%$ paro) & $17.175 \times 12.388$ & 211.905 .150 & \\
\hline Y Compensación JP75 & $65.625 \times 12.338 \times 0,25$ & 201.309 .893 & \\
\hline Z Compensación JP50 & $32.633 \times 12.338 \times 0,50$ & 201.309 .893 & \\
\hline U Gasto actual (2012) en desempleo & & 562.601 .000 & \\
\hline Coste total $=\mathrm{X}+\mathrm{Y}+\mathrm{Z}-\mathrm{U}$ & & 51.923 .935 & \\
\hline Incremento recaudación vía IRPF & $(32.000-12.338) \times 25.725 \times 0,24$ & 121.393 .188 & \\
\hline Nueva renta salarial JC & & 41.073 & \\
\hline Nueva renta salarial JP75 & $41.073 \times 0,75+12.338 \times 0,25$ & 33.889 & $82,51 \%$ \\
\hline Nueva renta salarial JP50 & $41.073 \times 0,50+12.338 \times 0,50$ & 26.706 & $65,02 \%$ \\
\hline Nueva renta media & & 38.200 & \\
\hline
\end{tabular}

Fuente: elaboración propia a partir de datos de Eustat. 
Consideramos también esta opción B como un posible escenario de llegada, aunque a corto plazo es de difícil ejecución: estamos considerando todo el gasto que se hace en desempleo, tanto a través de la administración estatal vía SEPE (subsidios y prestaciones por desempleo) como a través de las administraciones vascas (RGI, Renta de Garantía de Ingresos), por lo que habría que replantear las competencias en materia laboral y cambiar la legislación laboral vigente para ser llevada a cabo. Por otra parte, estamos considerando la media de horas trabajadas por todo tipo de personas activas, lo cual lleva a plantearse si una jornada parcial para un autónomo debe considerarse de la misma forma que para un asalariado.

En cualquier caso, lo que queremos señalar es que existen recursos para redistribuir las jornadas de trabajo y hacer disminuir el paro hasta niveles mínimos. En esta opción, las jornadas laborales a tiempo parcial quedan compensadas con rentas por desempleo, con lo que un trabajador a jornada del $75 \%$ recibiría una renta salarial total del $82 \%$ de un trabajador a tiempo completo, y los trabajadores a media jornada recibirían una renta igual al 65\% del trabajador a tiempo completo. Como señalan los expertos Feld et al. (2015), es mejor tener empleo (aunque sea un minijob) y ayudas hasta completar una renta digna, que recibir sólo asistencia.

\section{Propuesta de reducción del tiempo de trabajo para la población asalariada}

En esta sección presentamos una propuesta de RTT dirigida al empleo asalariado de Gipuzkoa, que viene a representar en torno a un $87 \%$ de la población ocupada y cuya evolución en el periodo 1995-2102 se describe brevemente a continuación. Como hemos adelantado en la introducción a este artículo, se trata de plantear una reducción homogénea de la jornada que posibilite un descenso en la tasa de desempleo hasta un nivel del 5\%. Para ello analizaremos el efecto redistributivo en los perceptores de renta que se verían afectados por la implantación de esta propuesta en (1) un caso de compensación total, en que los salarios se mantienen inalterados tras la reducción de la jornada y (2) un caso de compensación parcial, en que la reducción de la jornada se acompańa de una reducción salarial. Finalizamos el trabajo evaluando los resultados obtenidos por sectores.

\subsection{Evolución de la población asalariada en Gipuzkoa}

En la Figura 6 se ha recogido la evolución del empleo asalariado de Gipuzkoa en el periodo 1995-2102 a través de tres variables: Puestos de trabajo asala- 
Figura 6

\section{Empleo asalariado Gipuzkoa}

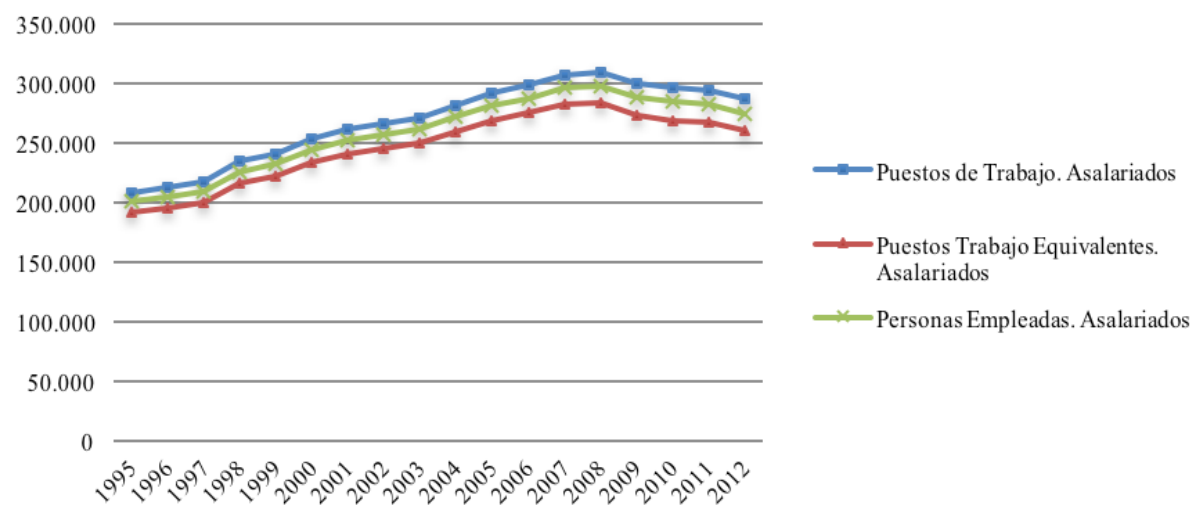

Fuente: Eustat.

riados, Personas empleadas asalariadas y Puestos de trabajo asalariados equivalentes a tiempo completo que se definen así:

- Puestos de trabajo asalariados: número de contratos de trabajo asalariado.

- Personas empleadas asalariadas: personas que ocupan uno o más puestos de trabajo asalariado. Como una misma persona puede ocupar más de un puesto de trabajo asalariado, el número de personas asalariadas siempre será igual o inferior al de puestos de trabajo asalariado.

- Puestos de trabajo asalariados equivalentes a tiempo completo (ETC): los puestos de trabajo asalariados equivalentes a tiempo completo se obtienen como cociente entre el total de horas asalariadas trabajadas y la jornada media anual de las horas trabajadas en puestos de trabajo asalariados a tiempo completo. La existencia de contratos a tiempo parcial hace que el número de ETC sea inferior al de puestos de trabajo; una mayor diferencia entre estas dos variables indica una mayor proporción de puestos de trabajo a tiempo parcial. El mayor número de ECT (283.746) se alcanza en 2008, habiéndose reducido en el año 2012 a 260.326, una caída del 8,25\% que lo deja en valores próximos al año 2004.

En la Figura 7 se recoge la participación creciente del empleo asalariado sobre el total del empleo, que ha pasado de situarse en torno a un $82 \%$ en 1995 a un $87 \%$ en 2012 . 
Figura 7

Participación del empleo asalariado en la ocupación de Gipuzkoa

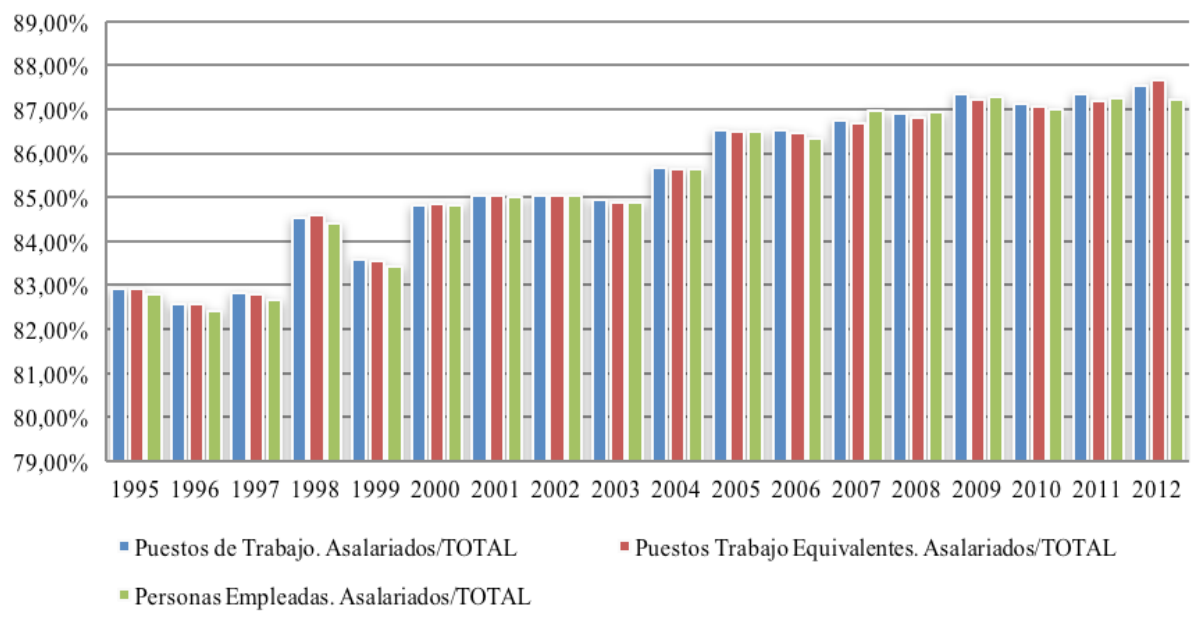

Fuente: Eustat.

\subsection{Efecto en el empleo de una reducción de la jornada}

Sin contemplar cambios en la productividad, en la población activa y/o en otras variables que podrían derivarse de una reducción de la jornada, calculamos el efecto que una reducción de la jornada media asalariada podría tener sobre el número de puestos de trabajo asalariados equivalentes a tiempo completo (ETC), siendo:

JM: jornada media asalariada anual a tiempo completo.

HT: horas totales anuales asalariadas.

SM: salario medio anual.

Como: $E T C=H T / J M \rightarrow J M . E T C=H T$

la derivada total de la expresión: $d(J M . E T C)=d H T$

Suponiendo que $H T$ no varía: $d H T=0 \rightarrow d(J M . E T C)=0$

$\rightarrow J M^{\prime} . E T C+J M \cdot E T C^{\prime}=0 \rightarrow E T C^{\prime} / E T C=-J M^{\prime} / J M$

Aproximando el resultado para valores discretos: $\triangle E T C / E T C=-\triangle J M / J M$.

Esta expresión indica que para mantener las HT, y sin contemplar cambios en la productividad y/o en otras variables que podrían derivarse de una reducción de la JM, se requiere una tasa de variación de los puestos de trabajo asalariados $(\triangle \mathrm{ETC} / \mathrm{ETC})$ del mismo valor $-\mathrm{y}$ de signo contrario- que la tasa de variación de la jornada $(\Delta \mathrm{JM} / \mathrm{JM})$. 
Por ejemplo, un $1 \%$ de reducción de la JM requeriría un incremento aproximado del $1 \%$ de los ETC para mantener las HT.

Figura 8

Jornada media anual asalariados Gipuzkoa

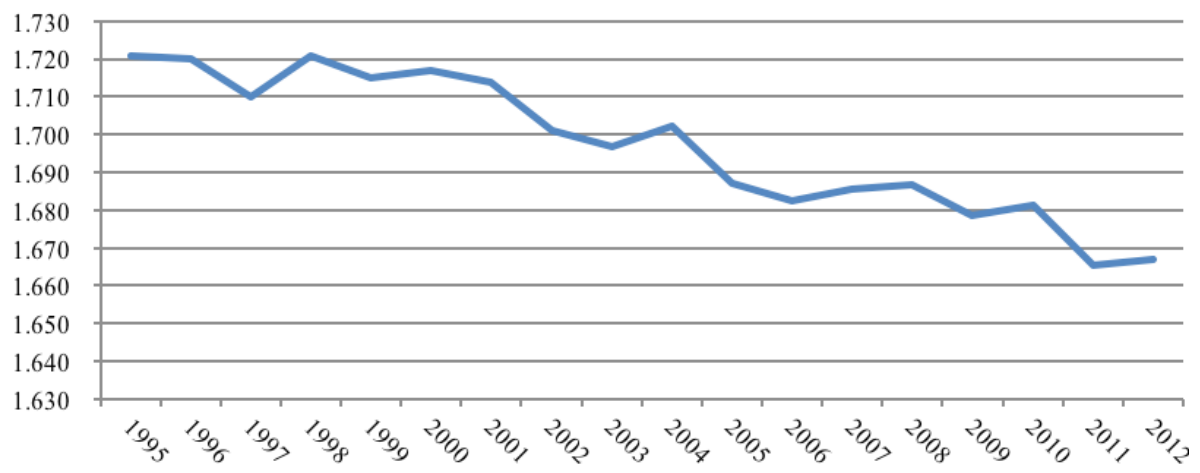

Fuente: Eustat.

\subsection{Efectos redistributivos de la creación de un puesto de trabajo por RTT}

La creación de un puesto de trabajo desde la perspectiva de una RTT —en la que como ya hemos advertido no contemplamos cambios en la productividad u otras variables-, se realiza en base a la reducción de la jornada que se aplique a la población empleada anteriormente, de modo que no hay incremento en las horas totales trabajadas ni en la producción de valor añadido ni tampoco en la renta. Lo que sí va a tener lugar es un cambio en la distribución de la renta ${ }^{5}$ que dependerá de diversos factores, como las prestaciones que viniera recibiendo la persona desempleada, la forma de financiar ese nuevo puesto de trabajo o cuáles sean los parámetros fiscales, con lo que nos podemos encontrar con multitud de escenarios distributivos.

Dejando al margen el efecto multiplicador que puede derivarse de una política de $\mathrm{RTT}^{6}$, cuestión que no vamos a abordar en este trabajo, su implantación va a ocasio-

5 Este cambio en la distribución va a ser generador de renta, porque la distribución resultante será más igualitaria y generará un efecto expansivo al aumentar el consumo y la demanda, pero no vamos a contemplar este efecto.

6 «En los últimos años, el interés por la equidad en la distribución de la renta y el papel de las políticas públicas se ha reavivado desde distintos ámbitos de la investigación y también por parte de los organismos internacionales, como la OCDE, la OIT y la propia UE, en un contexto mundial caracterizado por el aumento de las desigualdades incluso dentro de los países tradicionalmente más prósperos. Unido a lo anterior, la grave situación económica que está atravesando nuestro país, el deterioro de los ingresos de las familias, la caída de la demanda agregada, las dificultades de supervivencia de las empresas y el descenso de la recaudación refuerzan la oportunidad de la reflexión sobre la interacción entre la distribución de la renta y el crecimiento económico» (CES: 2013). 
nar un cambio en la redistribución de la renta que puede afectar a la población desocupada, a la población asalariada, a las empresas y a las administraciones públicas.

\section{Población desempleada}

Este colectivo percibe diferentes tipos de rentas de protección social; en la Figura 9 están recogidas las obtenidas por desempleo, vivienda y exclusión social, en la Figura 10 se ha desglosado el gasto en prestaciones de desempleo.

Figura 9

\section{Gasto en desempleo, vivienda y exclusión social en Gipuzkoa}

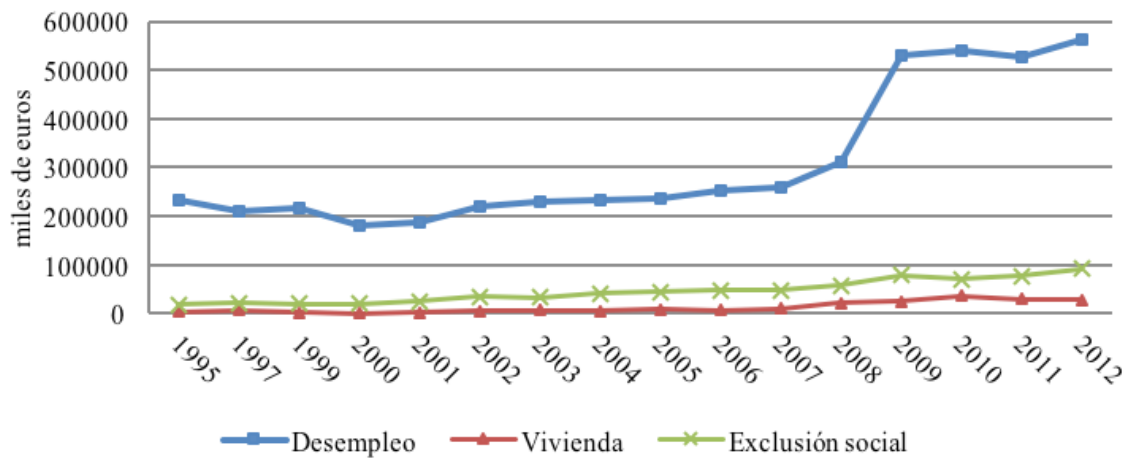

Fuente: Eustat.

Figura 10

Gasto en prestaciones de desempleo en Gipuzkoa

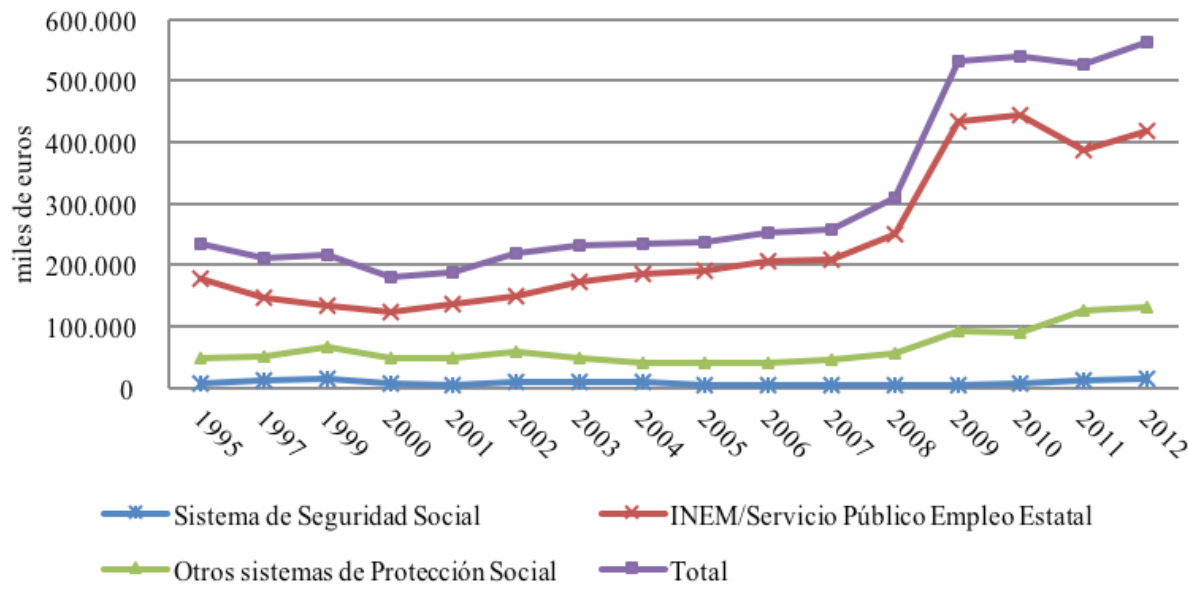

Fuente: Eustat. 


\section{Población asalariada}

Es el colectivo al que se le va a aplicar la reducción de la jornada.

- Empresas. Se van a ver afectadas por la firma de los nuevos contratos de trabajo que se deriven de la reducción de la jornada de sus empleados.

- Sector público. Vamos a contemplar los efectos de una RTT sobre el gasto en prestaciones por desempleo, sobre los ingresos fiscales (IRPF y Sociedades) y sobre la tesorería de la Seguridad Social.

\subsubsection{Contratación de un desempleado con prestación de desempleo}

Antes de contemplar distintas posibilidades de financiación —empresas, AAPP y/o población asalariada - para los nuevos puestos de trabajo, vamos a proceder a evaluar su impacto distributivo entre los primeros afectados, que van a ser (1) los nuevos contratados y (2) el sector público, y lo vamos a hacer para el caso en que la persona contratada viniera percibiendo alguna prestación de desempleo.

\section{Coste de contratación de un nuevo empleado a tiempo completo}

Lo estimamos por el salario medio bruto en Gipuzkoa, que fue de 41.073 euros anuales en 2012 (EUSTAT).

\section{Cálculo de la prestación media por desempleo}

Para estimar la prestación media que viene recibiendo una persona en situación de desempleo, vamos a tomar exclusivamente las prestaciones abonadas por el $\mathrm{SEPE}^{7}$ (418.517.000). Teniendo en cuenta que en el total del gasto se incluyen las cuotas pagadas a la Seguridad Social correspondientes a la empresa $(23,6 \%)$ por los beneficiarios de la prestación contributiva, y con la base sobre la que vinieran cotizando en el último empleo, hemos tomado como base de cotización el salario medio de Gipuzkoa, 41.073 euros brutos anuales, de los cuales, 7.842 euros corresponden a las cotizaciones de la Seguridad Social a cargo de la empresa. Como son 17.406 los beneficiarios de prestaciones contributivas, el total estimado de cuotas a la Seguridad Social que paga el SEPE es de (7.842 $\times 17.406) 127.538 .172$ euros que, deducidos del total del gasto, deja un ingreso a los beneficiarios de 290.978.828 euros. Dividiendo esta cantidad entre

7 De los 562.601.000 euros del total del gasto por desempleo en Gipuzkoa del año 2012, 418.517.000 (figura 10) corresponden al gasto en prestaciones de desempleo abonadas por el SEPE (Servicio Público de Empleo Estatal) para un total de 27.695 beneficiarios, de los cuales 17.406 reciben prestaciones contributivas. El resto del gasto, es decir, 144.084 .000 euros, se distribuye entre un número indeterminado de desempleados que también incluye a algunos de los 27.695 anteriormente señalados y de los que no existe información disponible. 
el total de los 27.695 usuarios, obtenemos una prestación media por usuario de 10.507 euros. En resumen:

- prestaciones abonadas por el SEPE:

418.517 .000

— cotizaciones de la Seguridad Social (a cargo de la empresa): 127.538 .172

- ingreso a los usuarios:

290.978 .828

- n. ${ }^{\circ}$ usuarios:

27.695

- prestación neta media por usuario:

\section{Variación neta en los ingresos de un nuevo empleado}

La variación neta la obtenemos por la diferencia entre los ingresos que obtendría del nuevo contrato y los que venía percibiendo como desempleado y se ha recogido en la Tabla 4, donde están descontadas las cuotas a la Seguridad Social a cargo del empleado (o beneficiario de prestación contributiva) y el IRPF ${ }^{8}$. La variación neta media por nuevo empleado es de 16.195 euros anuales.

Tabla 4

Variación neta en los ingresos de un nuevo empleado

\begin{tabular}{lrrr}
\hline \multicolumn{1}{c}{ Variación neta ingresos nuevo empleado (euros) } & Desempleado & $\begin{array}{c}\text { Nuevo } \\
\text { empleado }\end{array}$ & Variación \\
\hline Prestación neta desempleo & 10.507 & 0 & -10.507 \\
Salario (sin seguridad social a cargo de la empresa) & 0 & 33.230 & 33.230 \\
Cotizaciones a la seguridad social trabajador (4,7\%) & -982 & -1.562 & -580 \\
IRPF & -2.286 & -8.234 & -5.948 \\
\hline Ingresos netos & 7.239 & 23.434 & 16.195 \\
\hline
\end{tabular}

Fuente: elaboración propia a partir de datos de EUSTAT y SEPE.

\section{Variación neta en los ingresos de las AAPP}

a) Ahorro en prestaciones de desempleo: prestación media por desempleado que deja de abonarse en caso de un nuevo contrato de trabajo. Dividiendo el total del gasto en prestaciones del SEPE, 418.517.000 euros entre el total de 27.695 beneficiarios, el gasto medio que se ahorraría por cada nuevo contrato es de 15.111 euros anuales.

\footnotetext{
${ }^{8}$ Para el cálculo de IRPF se ha considerado un tipo medio de gravamen del $24 \%$ sobre las prestaciones de desempleo y un $26 \%$ sobre el salario, descontados en ambos casos el total de cuotas a la Seguridad Social.
} 
b) Ingresos adicionales en Tesorería de la Seguridad Social: diferencia entre cuotas pagadas por salario y las pagadas por prestación de desempleo. Para las cotizaciones a la Seguridad Social por asalariado contratado, se ha tomado el salario medio anual de 41.073 euros, obteniéndose unas cuotas de 7.842 euros y 1.562 euros a cargo de la empresa y del trabajador respectivamente. Para las cotizaciones por desempleado a cargo del SEPE, se han dividido los 127.538.172 euros mencionados anteriormente entre el total de 27.695 beneficiarios (no sólo los que reciben prestaciones contributivas) y el resultado medio es de 4.605 por beneficiario'; procediendo de la misma manera para las cuotas a cuenta del beneficiario (4,7\%), el resultado es de 982 euros. La variación en la Tesorería de la Seguridad Social resulta de 3.817 euros por empleado, tal y como se recoge en la Tabla 5.

Tabla 5

Variación en la Tesorería de la Seguridad Social por un nuevo empleado

\begin{tabular}{lccc}
\hline \multicolumn{1}{c}{ Tesorería Seguridad Social } & Desempleado & Empleado & Variación \\
\hline Cotizaciones SS a cargo empresa $(23,6)$ & 4.605 & 7.842 & 3.237 \\
Cotizaciones SS a cargo trabajador $(4,7)$ & 982 & 1.562 & 580 \\
\hline TOTAL & 5.587 & 9.404 & 3.817 \\
\hline
\end{tabular}

Fuente: elaboración propia a partir de datos de EUSTAT y SEPE.

c) Ingresos adicionales IRPF: diferencia entre el IRPF pagado por salario y el pagado por prestaciones de desempleo. Los mismos pagos por IRPF que hemos calculado en la Tabla 4, correspondiente a los nuevos empleados son ahora ingresos fiscales, un total de 5.948 euros en la Tabla 6.

Tabla 6

Variación en los ingresos de IRPF por un nuevo empleado

\begin{tabular}{lccc}
\hline Variación ingresos IRPF (euros) & Desempleado & Empleado & $\begin{array}{c}\text { Variación } \\
\text { total }\end{array}$ \\
\hline IRPF & 2.286 & 8.234 & 5.948 \\
\hline
\end{tabular}

Fuente: elaboración propia a partir de datos de EUSTAT y SEPE.

\footnotetext{
${ }^{9}$ La diferencia entre las 15.111 que paga el SEPE y las 10.507 que recibe el prestatario son las 4.605 de Seguridad Social a cargo de la empresa que asume el SEPE.
} 
En la Figura 11 se recogen los efectos anteriores agregados y se muestra el destino de los 41.073 euros del coste de contratación un nuevo asalariado.

\section{Figura 11}

Destino del coste salarial de un nuevo contrato

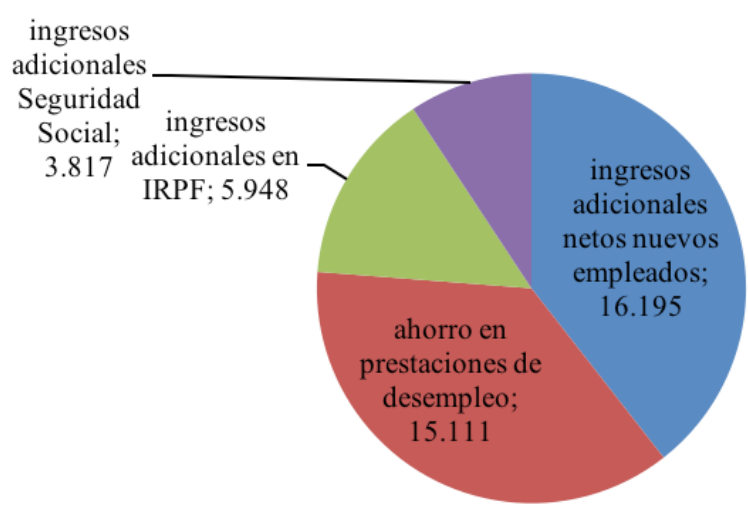

Fuente: elaboración propia a partir de datos de EUSTAT y SEPE.

\subsubsection{Asunción del coste salarial por la empresa contratante}

A continuación presentamos los resultados bajo el supuesto de que la empresa contratante soporta el coste salarial de forma íntegra. Puesto que va a verse afectado el beneficio de la empresa contratante, hay que tener en cuenta el im-

\section{Figura 12}

Efectos redistributivos de un nuevo contrato

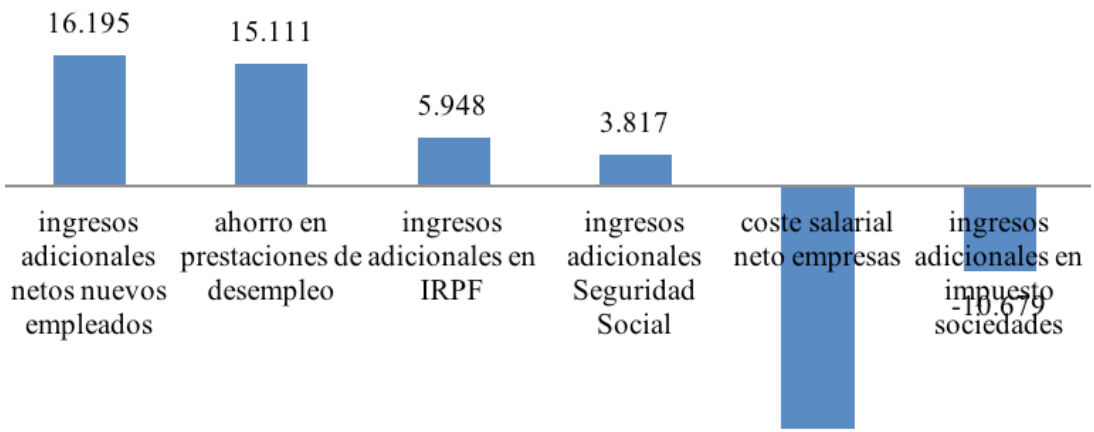

$-30.394$

Fuente: elaboración propia a partir de datos de EUSTAT y SEPE. 
pacto sobre el Impuesto de Sociedades. Hemos calculado el coste neto para la empresa descontando al coste total un tipo marginal de sociedades del $26 \%$, que es el tipo medio de sociedades en Gipuzkoa (se sitúa entre el 24\% y el 28\% dependiendo del tamaño de la empresa).

El coste neto para las empresas resulta 30.394 euros como diferencia entre los 41.073 del coste total y los 10.677 que corresponderían marginalmente al impuesto de sociedades. La nueva distribución de ingresos se recoge en la Figura 12.

Es de destacar que, en en este caso, el resultado para la Hacienda Foral de Gipuzkoa ya no es positivo (5.948 IRPF) sino negativo: 5.948 IRPF -10.677 Impuesto Sociedades $=-4.733$ euros. El resto del sector público (SEPE y Seguridad Social) obtendría unos ingresos adicionales de: 15.111 $(\mathrm{SEPE})+3.819($ Seguridad Social $)=18.928$ euros por ETC. El efecto agregado sobre el conjunto del sector público es de 14.199 euros.

La distribución del coste neto para las empresas (30.394 euros) se recoge en la Figura 13: 30.394 (empresas) $=16.195$ (nuevos empleados) +14.199 (sector público)

Figura 13

Destino del coste salarial neto de un nuevo contrato

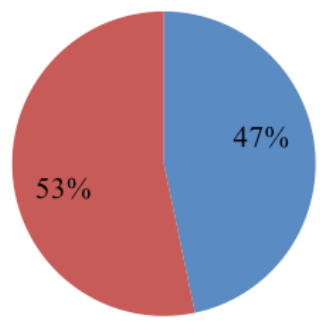

- ingresos adicionales sector público

ingresos adicionales netos nuevos empleados

Fuente: elaboración propia a partir de datos de EUSTAT y SEPE.

\subsubsection{Contrato de desempleados sin prestación de desempleo}

En los cálculos anteriores hemos estimado que el nuevo empleado venía recibiendo una prestación media de desempleo de 15.111 euros anuales (incluída la Seguridad Social a cargo de la empresa que paga el SEPE). Si se tratara de un desempleado que no estuviera recibiendo ningún tipo de ayuda o prestación, el coste salarial neto del Impuesto de Sociedades para la empresa seguiría siendo de 30.394 euros y su distribución se recoge en la Figura 14. En la Figura 15 se ha representado el efecto redistributivo agregado:

30.394 (empresas) = 23.435 (nuevos empleados) + 6.959 (sector público) 


\section{Figura 14}

Efecto redistributivo de un nuevo contrato en el caso que el nuevo empleado no viniera percibiendo ningún tipo de ayuda o prestación

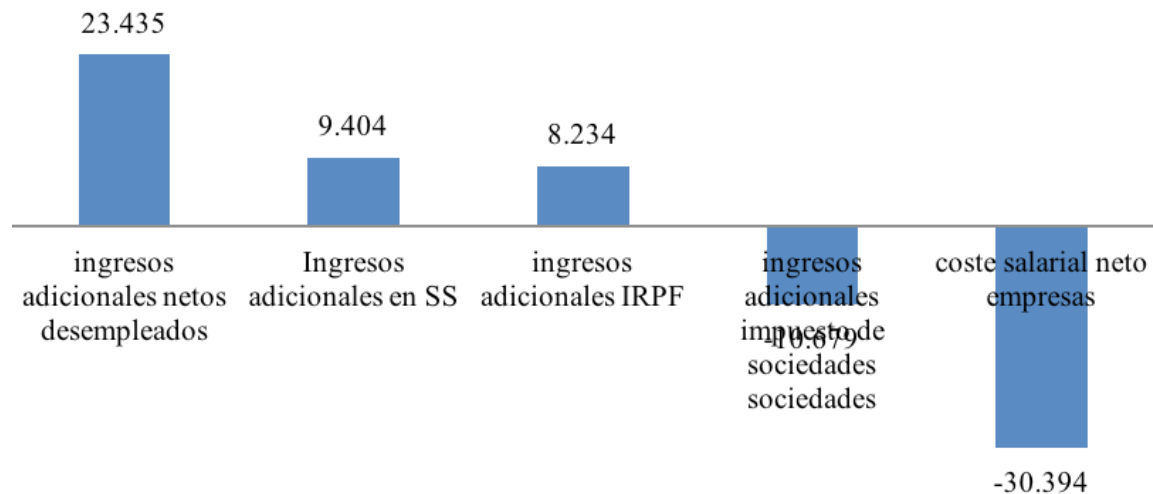

Fuente: elaboración propia a partir de datos de EUSTAT y SEPE.

Figura 15

Destino del coste salarial neto de un nuevo contrato cuando el nuevo empleado no viniera percibiendo ningún tipo de ayuda o prestación

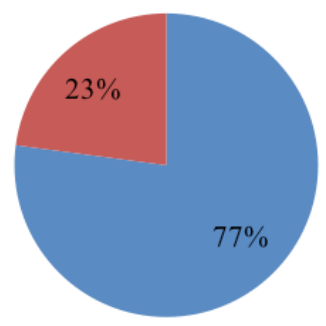

$$
\begin{aligned}
& \text { ingresos adicionales netos } \\
& \text { desempleados } \\
& \text { ingresos adicionales sector } \\
& \text { público }
\end{aligned}
$$

Fuente: elaboración propia a partir de datos de EUSTAT y SEPE.

\subsection{Propuesta de RTT para una reducción de la tasa de desempleo al 5\%}

En este apartado vamos a contemplar una reducción homogénea de la jornada (JMA) en toda la población asalariada de Gipuzkoa simultánea a un aumento de los puestos de trabajo asalariados a tiempo completo (ETC), bajo el supuesto de que la relación entre las tasas de variación de ambas variables se mantiene en un valor aproximado $\triangle E T C / E T C=-\triangle J M / J M$. 


\subsubsection{Reducción de la de la jornada}

En la Tabla 7 se recogen datos de actividad, ocupación y paro de trabajo de Gipuzkoa para el año 2014 (Eustat) correspondientes a una tasa de paro del 12,49\%, y las cifras que resultarían de reducirse la tasa de desempleo a un nivel de paro friccional del 5\% sobre la misma población activa, semejante al nivel de desempleo en Gipuzkoa entre 2008 y 2009 (Figura 16: Evolución de la tasa de paro en Gipuzkoa).

Tabla 7

Población activa, ocupada y parada en 2014 y con tasa de paro del 5\%

\begin{tabular}{lcc}
\hline \multicolumn{1}{c}{ Gipuzkoa } & Situación actual & Escenario de llegada \\
\hline Población activa & 343.500 & 343.500 \\
Ocupados & 300.500 & 326.230 \\
Parados & 42.900 & 17.175 \\
Tasa de paro & $12,49 \%$ & $5 \%$ \\
\hline
\end{tabular}

Fuente: elaboración propia a partir de datos de EUSTAT y SEPE.

Figura 16

Evolución de la tasa de paro en Gipuzkoa

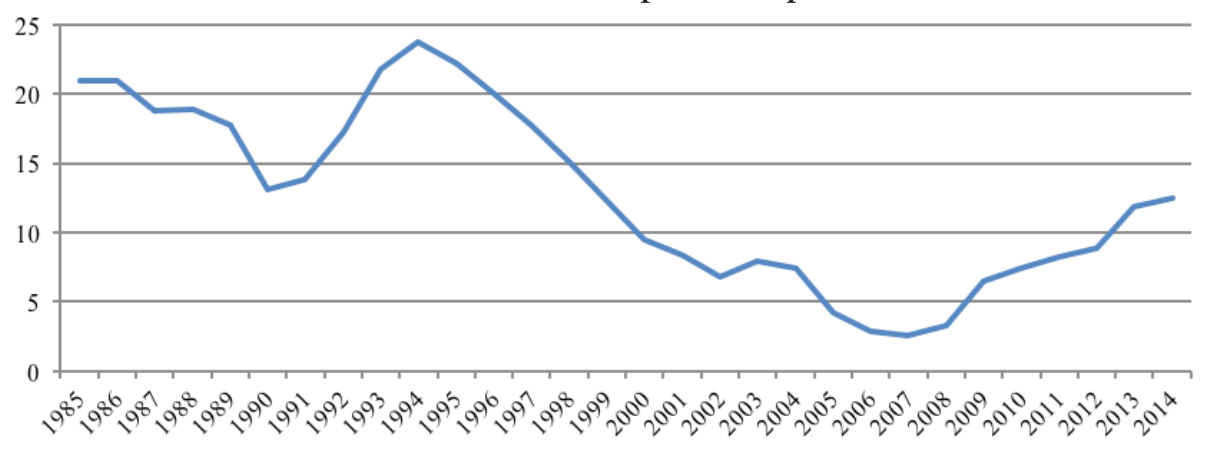

Fuente: Eustat.

A partir de los datos recogidos en la Tabla 7, calculamos el número de nuevos puestos de trabajo (PTE) asalariados necesarios para alcanzar una tasa de paro del 5\%. Hay que observar que, dado que toda la nueva contratación se contempla a tiempo completo, se vería reducida la tasa de parcialidad, tanto entre los asalariados como en el conjunto de la población ocupada.

- Nuevos contratos asalariados a tiempo completo: $42.900-17.175=$ 25.735 PTE.

—PTE asalariados Gipuzkoa 2012: 260.330.

—Proporción de los 25.735 PTE: 25.735/260.330 = 9,9\%. 
Como los 25.773 PTE representan un 9,9\% del total de PTE asalariados, habría que reducir la jornada media aproximadamente un 9,9\%

— Jornada media anual asalariados $2012=1.670$ horas.

- Nueva jornada media anual: $90,1 \%$ de $1.670=1.505$ horas.

— Nueva jornada media semanal: $90,1 \%$ de 40 horas semanales $=36$ horas.

\subsubsection{Financiación y efectos distributivos}

A partir de los resultados obtenidos en el epígrafe 3.3.2, y teniendo en cuenta que para reducir la tasa de desempleo al $5 \%$ haría falta contratar 25.773 asalariados a tiempo completo, pasamos a calcular el coste total y los efectos redistributivos de esta propuesta en dos escenarios. En el primero, la reducción de la jornada se implementa sin ningún tipo de reducción salarial — compensación total_- en el segundo, la reducción de un 10\% en la jornada se acompaña de una reducción salarial —compensación parcial- del 5\% y de una revisión de la base de cotización del impuesto de sociedades.

\section{a) Reducción de la jornada con compensación total}

Este escenario, en el que las empresas asumen las reducciones de jornadas y los mayores costes salariales debidos a la contratación de nuevos empleados es el que, como ya hemos señalado en el epígrafe 1.2, Alonso y Pérez, 1996 denominan vertiente de compensación total. En la Tabla 8, se presenta el coste neto total soportado por las empresas y su destino.

Tabla 8

Efecto redistributivo de una reducción del 9,9\% de la jornada sin reducción salarial

\begin{tabular}{|c|c|c|c|}
\hline Destino del coste neto de un PTE & 25.730 PTE & Coste neto de un PTE & 25.730 PTE \\
\hline $\begin{array}{l}\text { Ingresos adicionales netos del } \\
\text { nuevo empleado: } 16.195\end{array}$ & 417.393 .735 & $\begin{array}{c}\text { Coste neto empresas de } \\
\text { un nuevo contrato: } 30.394\end{array}$ & 783.344 .562 \\
\hline $\begin{array}{l}\text { Ahorro prestaciones desempleo: } \\
15.111\end{array}$ & 389.455 .803 & & \\
\hline $\begin{array}{l}\text { Ingresos adicionales en Tesorería } \\
\text { Seguridad Social: } 3.817\end{array}$ & 98.375 .541 & & \\
\hline Ingresos adicionales IRPF: 5.948 & 153.297 .804 & & \\
\hline $\begin{array}{l}\text { Ingresos adicionales impuesto so- } \\
\text { ciedades: }-10.677\end{array}$ & -275.178 .321 & & \\
\hline
\end{tabular}

Fuente: elaboración propia a partir de datos de EUSTAT y SEPE. 
El efecto distributivo agregado resulta:

— Ingresos adicionales sector público: 365.950.827.

— Ingresos adicionales empresas: -783.344 .562 .

— Ingresos adicionales población desempleada: 417.393.735.

\section{b) Reducción de la jornada con compensación parcial}

Siguiendo a los mismos autores (Alonso y Pérez: 1996), en este otro supuesto se contempla una RTT en su vertiente de compensación parcial en el que las nuevas horas libres sólo dejan de pagarse en parte «registrándose en consecuencia un aumento de las ganancias por hora y una disminución de los salarios por persona; y ello siempre en menor proporción que el tiempo reducido" (81). Planteamos para la reducción de un $10 \%$ en la jornada una reducción salarial del $5 \%$.

- Reducción Salarial del 5\%.

- Salarios 2012: 10.692.469.000.

- Salarios nuevos contratos (10\% de 10.692.469.000): 1.069.246.900.

- Salarios totales: $10.692 .469 .000+1.069 .246 .900=11.761 .715 .900$.

— $5 \%$ reducción salarial (5\% de 11.761.715.900): 588.085.795.

A partir de este valor de 588.085 .795 euros de reducción salarial, y aplicando los ajustes en IRPF, cotizaciones a la SS, e impuesto de sociedades, obtenemos el coste neto final que se detalla en la Tabla 9.

Tabla 9

Efecto redistributivo de una reducción del $9,9 \%$ de la jornada con $5 \%$ de reducción salarial

\begin{tabular}{lr|lc}
\hline \multicolumn{2}{c|}{ Destino del coste neto } & \multicolumn{2}{c}{ Coste neto } \\
\hline $\begin{array}{l}\text { Ingresos adicionales netos pobla- } \\
\text { ción desempleada }\end{array}$ & 387.208 .396 & Coste neto empresas & 348.542 .412 \\
\hline Ahorro prestaciones desempleo & 389.476 .589 & $\begin{array}{c}\text { Disminución ingresos po- } \\
\text { blación asalariada }\end{array}$ & 305.038 .147 \\
\hline $\begin{array}{l}\text { Ingresos adicionales en Tesorería } \\
\text { Seguridad Social }\end{array}$ & -36.148 .928 & \\
\hline Ingresos adicionales IRPF & 35.505 .349 & \\
\hline $\begin{array}{l}\text { Ingresos adicionales Impuesto de } \\
\text { Sociedades }\end{array}$ & -122.460 .847 & & \\
\hline
\end{tabular}

Fuente: elaboración propia a partir de datos de EUSTAT y SEPE. 
El efecto distributivo agregado resulta:

—Ingresos adicionales sector público: 266.372.163 (una reducción del 27\% frente al caso de "compensación total»).

—Ingresos adicionales empresas: -348.542.412 (una reducción del 56\% frente al caso de "compensación total»).

- Ingresos adicionales población desempleada: 387.208 .396 (una reducción del $7 \%$ frente al caso de "compensación total»).

—Ingresos adicionales netos población asalariada :-305.038.147.

\section{Población asalariada}

Como hemos apuntado en el epígrafe 1.2, Riechmann y Recio (1997) argumentan que una RTT con compensación parcial — reducción del salario total, aumento del salario hora- puede aceptarse siempre que «no empeore la distribución global de rentas en detrimento de los trabajadores y que no disminuyan los salarios más bajos (2)» (57), aspecto que quedaría cubierto en este caso, dado que:

1. El salario total disminuye un 5\%, pero el salario/hora aumenta un $4,9 \%$ :

— salario/hora $=$ salario total $/$ jornada;

— tasa variación salario/hora = tasa variación salario total-tasa de variación jornada;

- tasa variación del salario/hora $=-5 \%-(-9,9 \%)=4,9 \%$.

2. La reducción de los salarios (305.038.147) resulta inferior a los ingresos adicionales que obtienen los nuevos empelados (387.208.396).

Los 257.513.119 euros que directamente obtiene el Sector Público de la aplicación del RTT podrían destinarse en parte para compensar los 305.038.147 euros de coste en los salarios más bajos.

\section{Revisión de la base de cotización del Impuesto de Sociedades}

En Castrillón et al., 2016b se ha estimado un tipo de gravamen efectivo sobre el excedente neto de explotación del PIB del 4,8\% en el año 2012, mientras que en ese mismo año el tipo medio efectivo sobre las rentas netas del trabajo contabilizadas en el PIB resultaba un 15,9\%. Una revisión de las bases de cotización del Impuesto de Sociedades que elevara el tipo efectivo del 4,8\% al 8,5\% generaría unos ingresos fiscales adicionales de 348.542 .412 euros:

Excedente neto explotación PIB pm 2012: 9.476.306.000 euros

$$
(0,085-0,048) \times 9.476 .306 .000=348.542 .412 \text { euros }
$$


Estos ingresos adicionales en el Impuesto de Sociedades podrían utilizarse para sufragar (o compensar de forma discriminada teniendo en cuenta la participación relativa del trabajo en cada empresa u otros criterios) los costes de contratación en las empresas, de manera que fuera la revisión de la base de cotización, y no las empresas contratantes, la que financiara la RTT.

\subsubsection{Resultados por sectores}

Pasamos a presentar los principales resultados obtenidos para el conjunto de Gipuzkoa desagregados por sectores económicos cuando la reducción de la jornada se orienta hacia una recuperación de la tasa de desempleo del 5\% sin reducción salarial (compensación total).

Figura 17

Efectos redistributivos de una reducción de la jornada del 9,9\% sin reducción salarial, por sectores

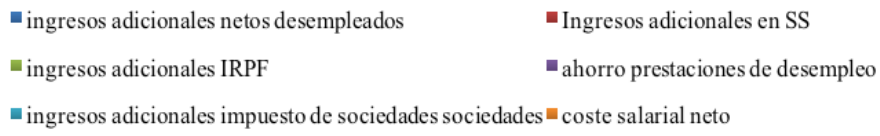

ॠ ingresos adicionales impuesto de sociedades sociedades ${ }^{\varpi}$ coste salarial neto

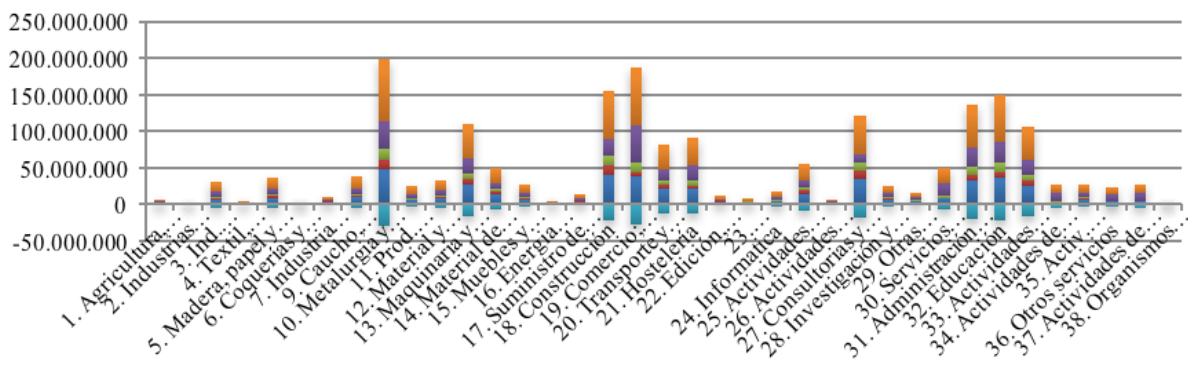

Fuente: elaboración propia a partir de datos de EUSTAT y SEPE.

\section{Sectores estratégicos}

En Castrillón et al., 2016c se han identificado los sectores en los que se dan las mejores condiciones macroeconómicas para una política de RTT que, si bien es posible en empresas y entornos de todas las ramas de actividad, muestra situaciones sectoriales de carácter estructural y coyuntural, las cuales se han tratado de sintetizar en los indicadores allí expuestos. No debemos olvidar que, más allá de esta categorización según su viabilidad sectorial agregada, las políticas de RTT capaces de repartir los empleos y generar marcos de vida laboral menos duales - entre quienes tienen un trabajo remunerado y quienes no- son cuestión de las prioridades que se establezcan en la negociación colectiva y, sobre- 
Figura 18

Distribución de los 25.773 PTE, por sectores

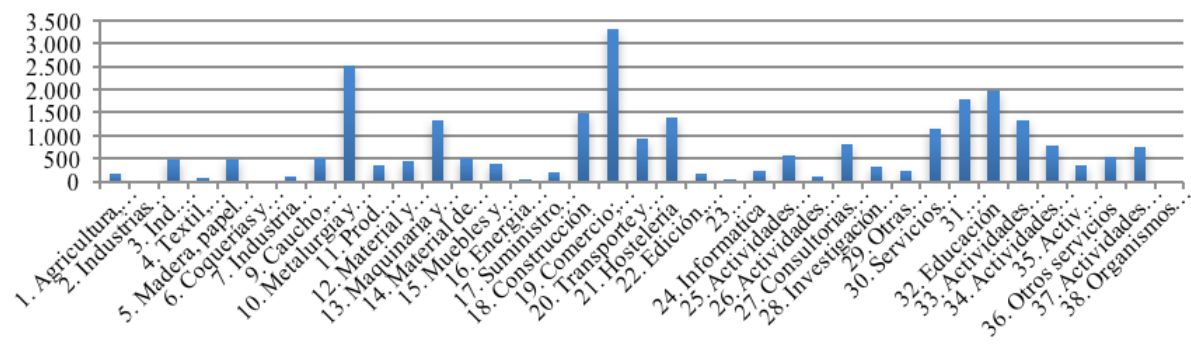

Fuente: elaboración propia a partir de datos de EUSTAT y SEPE.

todo, de los frentes de movilización que surjan desde los trabajadores y trabajadoras y sus organizaciones.

Aún así, las condiciones macroeconómicas y la evolución de los indicadores laborales sectoriales marcan las bases materiales de dichas negociaciones y conflictos y, por tanto, nos permiten establecer tres zonas o grupos de sectores según la viabilidad de las políticas de RTT.

- Zona 1: Mayor viabilidad de politicas de RTT

Maquinaría y equipo; Transporte y almacenamiento; Actividades financieras y seguros; Administración pública y defensa y Actividades sanitarias.

- Zona 2: Sectores con puntos a favor y en contra para una politica de RTT

Construcción; Comercio y reparación de vehículos; Hostelería y Servicios auxiliares y Material de Transporte.

- Zona 3: Peores condiciones para una viabilidad de politicas de RTT

Agricultura, ganadería y pesca; Metalurgia y productos metálicos; Consultorías y actividades técnicas; Educación; Servicios sociales y Actividades de los hogares.

Presentamos a continuación los resultados agregados para los 10 sectores industriales situados en las zonas 1 y 2 considerados estratégicos. En la figura 19 se muestra que el número de puestos de trabajo resultante de una reducción de la jornada del 9,9\% con creación de empleo es de 13.740 , un $53 \%$ de los 25.773 que resultaban de una RTT para el conjunto de Gipuzkoa. 


\section{Figura 19}

\section{Efecto en el empleo en los 10 sectores estratégicos}

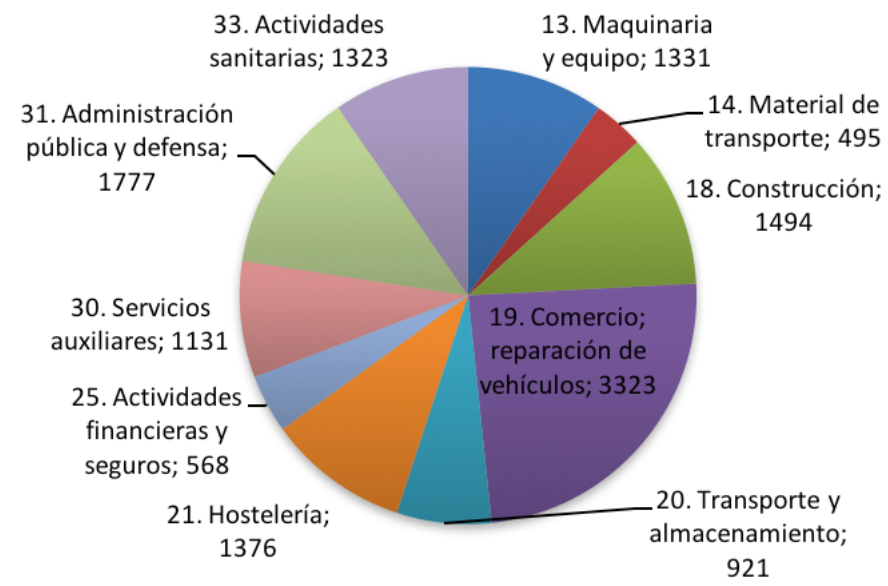

Fuente: elaboración propia a partir de datos de EUSTAT y SEPE.

\section{a) Compensación total}

Los efectos redistributivos agregados de una creación de $10 \%$ de puestos de trabajo con compensación total (sin reducción salarial) en los sectores estratégicos para una RTT en Gipuzkoa se muestran en la figura 20.

\section{Figura 20}

Efectos redistributivos en los 10 sectores estratégicos

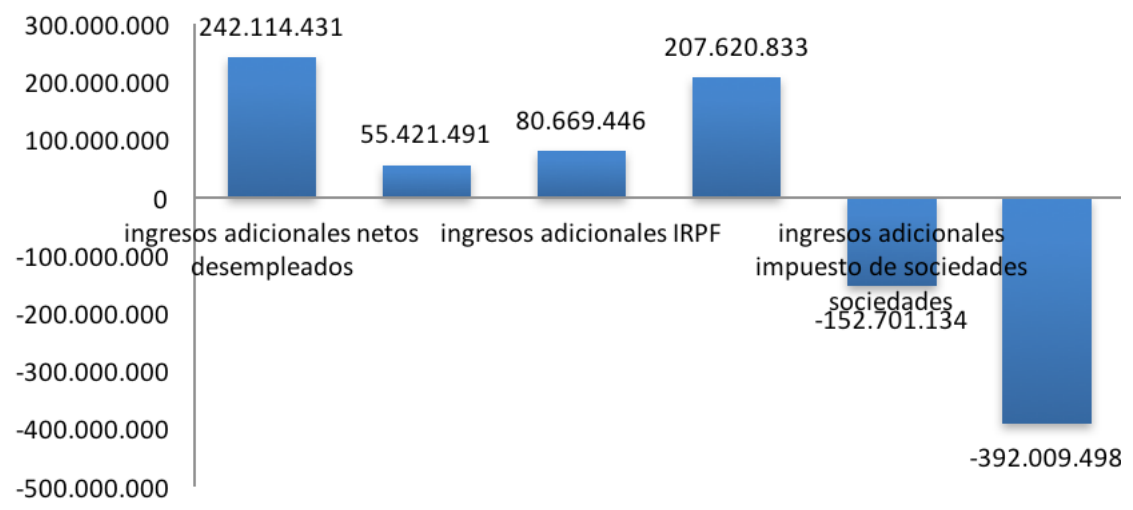

Fuente: elaboración propia a partir de datos de EUSTAT y SEPE. 


\section{b) Compensación parcial}

Para estimar los resultados con una reducción salarial del 5\% en los 10 sectores estratégicos, aplicamos las variaciones observadas en los resultados agregados entre ambos casos (compensación total y parcial, epígrafe 3.4.2.2).

- Ingresos adicionales sector público:

Compensación total: $55.421 .491+80.669 .446+207620.833$ $152.701 .134=191.010 .636$

Compensación parcial (una reducción del 27\% ): 139.437 .764

- Ingresos adicionales empresas:

Compensación total: -392.009 .498$

Compensación parcial (una reducción del 56\%): -172.484.179

- Ingresos adicionales población desempleada:

Compensación total: 242.114 .431

Compensación parcial (una reducción del 7\%): 225.166.420

- Ingresos adicionales población asalariada (por reducción salarial):

Compensación total: 0

Compensación parcial: este resultado lo estimamos por diferencia con los anteriores

Suma cero:

1.1.764 - 172.484.179 + 225.166.420 + Ingresos adicionales pob. asalariada $=0$ Ingresos adicionales netos población asalariada $=-192.120 .005$

La reducción de los salarios (192.120.005) resulta inferior a los ingresos adicionales que obtienen los nuevos empelados (225.166.420).

Los 139.437.764 euros que directamente obtiene el Sector Público de la aplicación del RTT podrían destinarse en parte para compensar los 192.120.005 euros de coste en la población asalariada de renta más baja.

\section{Conclusiones}

En el Apartado 1 hemos planteado los principales elementos de diagnóstico del problema que se quiere resolver: la cronificación del desempleo y la proliferación del sub-empleo. Hemos atendido al sesgo estructural de esta cuestión por sexos y generaciones. También hemos dado una leves pistas de la importancia de plantearse esta cuestión desde el marco laboral y normativo del territorio. Es decir, hemos visto que las opciones para hacer políticas de RTT son, aún ilimitadas, variadas en cuanto a la escala y medidas posibles. En este apartado simplemente hemos cartografiado los principales indicadores socio-laborales, cerrando 
con una serie de cuestiones técnicas para proyectar la incidencia de la RTT sobre cuestiones productivas y de potencial efecto de creación de nuevos empleos.

En el diagnostico hemos vuelto a identificar los focos de atención de nuestras propuestas, que es resolver de forma consistente el aumento masivo del empleo tras la destrucción de más de 60.000 empleos industriales y 32.000 en la construcción sólo entre 2008 y 2014 — ver indicadores para Bizkaia, Gipuzkoa y Araba en Fuente, de la et al. (2016a)_. Hemos visto que el paro de larga duración aumenta si se tiene en cuenta la inactivación así como el número de parados sin cobertura de desempleo activos que no reciben prestaciones ni subsidios. Este desempleo — que afecta a jóvenes de forma generalizada - tiene su contraparte en la creciente activación y sub-empleo de las mujeres, con tasas de parcialidad que aumentan trimestre a trimestre y con creciente involuntariedad. Hemos hecho algunas apreciaciones sobre el empleo parcial, claramente orientado en todo Europa a las mujeres, remarcando el rol de refuerzo del reparto sexista del trabajo que esto implica. Así mismo las horas extras son, en Espańa, crecientemente no pagadas y concentradas en un contexto de infra-utilización general de las fuerzas productivas en las economías española, vasca y gipuzkoana.

Este primer apartado ha concluido dando alguna pinceladas a cuestiones sociolaborales y productivas referentes a las relaciones entre RTT, productividad, creación de empleo, uso de los equipos y otras cuestiones organizativas. Hemos abordado en qué medida la RTT puede tener los efectos positivos que se esperaría de una traslación del tiempo liberado a nuevos puestos de trabajo. También hemos dado especial importancia a clarificar en toda estrategia de RTT la cuestión de la compensación salarial, o quién financia el aumento del coste laboral. Nuestra posición es partidaria de una RTT sustancial, redistributiva - financiada por el capital y los grandes salarios y, en menor medida, los intermedios - y equitativa - que sea para la mayoría y no genere dualidad en los puestos de trabajo-.

En el apartado 2 la RTT se ha aplicado sobre toda la población ocupada —asalariados y autónomos_- obteniéndose que habría que reducir la jornada media actual en torno al 10\% para alcanzar un nivel de paro friccional del 5\%. En caso de implementarse este hipotético escenario, se incorporarían al empleo los trabajadores que actualmente se encuentran desempleados. Consideramos que a partir de la situación actual es difícil realizar los cambios pertinentes para que se diera esta transformación de alto calado, puesto que el coste de la incorporación al trabajo de los parados tendría que ser pagado por los propios trabajadores — vía reducción de salarios - o por las empresas — haciéndose cargo de los nuevos contratos-, lo que nos sitúa en la dicotomía propia de la economía capitalista en la que se da un conflicto de intereses entre trabajo y capital (Arrizabalo, 2014). Es verdad que en esta opción se reduciría drásticamente el gasto social por desempleo, pero ello no compensaría el coste total de las nuevas contrataciones. 
Se ha esbozado un segundo escenario hipotético, en el que se asume que la jornada actual de un trabajador a tiempo completo no se reduce, pero en el que se admite un cierto nivel de parcialidad de los trabajadores - hemos tomado como hipótesis un $20 \%$ de trabajadores con tres cuartos de jornada, y un $10 \%$ de trabajadores a media jornada, con lo que se seguiría cubriendo el total de horas trabajadas en la actualidad - Para este segundo caso, hemos considerado que el ahorro en gasto por desempleo — que se reduciría hasta atender al 5\% de paro friccional — podría dedicarse a compensar a los trabajadores a tiempo parcial, con lo que dejarían de estar penalizados en parte aquellos trabajadores con jornadas parciales que desean trabajar a jornada completa. El mayor problema para poder aplicar este tipo de medidas es la distribución competencial entre las administraciones, puesto que actualmente los subsidios de desempleo dependen de la Seguridad Social, mientras que las rentas de garantía de ingresos dependen de la administración autónoma vasca.

En el apartado 3 se ha planteado un RTT dirigida exclusivamente al empleo asalariado de Gipuzkoa - que representa en torno al 87\% del total de la población ocupada-, con reducción homogénea de la jornada y creación de puestos de trabajo a tiempo completo (PTE asalariados) y se han obtenido los resultados que señalamos a continuación.

Para crear empleo mediante un RTT, la tasa de reducción de la jornada tiene que ser equivalente a la tasa de creación de puestos de trabajo a tiempo completo. Si se pretende reducir el paro al 5\%, habría que crear 25.735 PTE, lo que supone un incremento de en torno al 10\% de los PTE asalariados existentes que exigiría una reducción del 10\% en la jornada que quedaría en 36 horas semanales.

Si la reducción de la jornada se realiza en la vertiente de compensación total —sin reducción salarial_, el coste para las empresas resulta de unos 783 millones de euros, siendo las proporciones de destino del 53\% para los nuevos empleados — 417 millones de euros_ - y 47\% para el sector público — 316 millones de euros-.

En la vertiente de compensación parcial, con una reducción salarial del 5\%, el coste resulta ahora de unos 348 millones para las empresas y de 305 millones para los asalariados _ por reducción salarial_-, y el destino: 387 millones para los nuevos empleados y 266 millones para el sector público. En este caso, una revisión de las bases en el impuesto de sociedades que posibilitara la elevación de la presión fiscal efectiva sobre el excedente neto del 4,8\% actual al 8,5\%, además de resultar más equitativa con la presión fiscal efectiva sobre salarios $(15,9 \%)$, permitiría una recaudación de 348 millones, equivalente al coste de las empresas y con la que se podría acometer una financiación de las cargas progresiva con el beneficio en lugar de vinculada al número de empleados. Los ingresos adicionales que obtiene el sector público pueden ser destinados a compensar las pérdidas salariales de los asalariados con ingresos más bajos. En el caso de los 
sectores estratégicos, los resultados se mantienen aproximadamente y representan en torno al 50\% del total de Gipuzkoa.

Consideramos que profundizar en lo expuesto en este artículo es clave para el diseño de políticas de RTT en Gipuzkoa. En este sentido creemos que sería necesario hacer un estudio más detallado de los sectores escogidos como de mayor aplicabilidad de este tipo de medidas. Concretamente, las siguientes tareas a partir de este trabajo deberían ser:

- Realizar un estudio por subsectores, y más específicamente, por empresas, con el fin de detectar la existencia de convenios o contratos con jornadas laborales específicas - abandonando por tanto las medias sectoriales que hemos utilizado-.

- Por otro lado, sería conveniente delimitar el estudio entre empresas grandes y pequeñas, por ejemplo, de más —o menos- de 20 trabajadores, cifra considerada en la Ley Aubry como umbral para la aplicación progresiva de la reducción de jornadas en Francia.

\section{Bibliografía}

Alonso, Luis Enrique y PÉREz, Lourdes (1996): ¿Trabajo para todos?: Un debate necesario. Madrid: Ediciones Encuentro.

Álvarez, Ignacio, Luengo, Fernando y Uxó, Jorge (2013): Fractura y crisis en Europa. Madrid: Clave intelectual.

Aranguren, María José, Navarro, Mikel y Peña, Iñaki (2013): «¿Una crisis y una salida diferente? El caso de la Comunidad Autónoma del País Vasco", Papeles de Economía Española, 138, 160-177.

Arrizabalo Montoro, Xabier (2014): Capitalismo y Economía Mundial: Bases teóricas y análisis empirico para la comprensión de los problemas económicos del siglo XXI, Madrid, Instituto Marxista de Economía, 720 p.

AzNAR, Guy (1994): Trabajar menos para trabajar todos. Madrid: HOAC.

BengoetxeA, Aitor (2016): «Régimen jurídico básico de las materias directamente vinculadas a la reducción del tiempo de trabajo", Lan Harremanak. Revista de Relaciones Laborales, n. ${ }^{\circ} 34,2016$ (1)

Berbel, Sara (2015, 3 de septiembre): «Contratos a tiempo parcial: ¿oportunidad o trampa para las mujeres?», eldiario.es http://www.eldiario.es/agendapublica/impacto_ social/Contratos-tiempo-parcial-oportunidad-mujeres_0_364664454.html

Bilbao, Javier (2013): «Salarios y costes laborales unitarios en la economía española», Lan Harremanak. Revista de Relaciones Laborales, n. ${ }^{\circ} 27,12-34$.

Carrasco, Cristina (1995): «Un mundo también para nosotros», Mientras tanto (60), 11 19.

Castrillón, Verónica, Zendoia, Jose Mari y Zubiri, Jon Bernat (2016a): «Diagnóstico del empleo en Gipuzkoa», Lan Harremanak. Revista de Relaciones Laborales, 34$2016(1)$. 
Castrillón, Verónica, Zendoia, Jose Mari y Zubiri, Jon Bernat (2016b): «Distribución funcional de la renta y costes laborales en Gipuzkoa: un estudio empírico para la reducción del tiempo de trabajo", Lan Harremanak. Revista de Relaciones Laborales, 342016 (1).

Castrillón, Verónica, Zendoia, Jose Mari y Zubiri, Jon Bernat (2016c): «Indicadores socio-laborales y viabilidad sectorial de la reducción del tiempo de trabajo en Gipuzkoa", Lan Harremanak. Revista de Relaciones Laborales, 34-2016 (1).

CES, Consejo Económico y Social España (2013): Informe 03/2013 Distribución de la renta en España: desigualdad, cambios estrructurales y ciclos, CES España.

De la Fuente, Mikel y Zubiri, Jon Bernat (2016): «Significado histórico y actualidad de las políticas de reducción del tiempo de trabajo». Lan Harremanak. Revista de Relaciones Laborales, 34-2016 (1).

Durán, Jose (2015): «Horas extras: el mayor robo de la historia», Diagonal (254), https:// www.diagonalperiodico.net/global/27822-horas-extra-mayor-robo-la-historia.html

ELA (2015): Análisis de coyuntura, $n .^{\circ}$ 128. Manu Robles-Arangiz institutoa.

ETUI, E.T. (2014): Benchmarking Working Europe. Bruselas: ETUI.

EUSTAT (2015): Encuesta de Población Activa en Relación con la Actividad (EPRA), Tercer trimestre del 2015. EUSTAT.

Feld, Lars P., Otero, Miguel y Weigert, Benjamín (2015 15-Octubre): Los «minijobs» de Alemania. El Pais. http://elpais.com/elpais/2015/10/02/opinion/ 1443804516_787263.html

Gadrey, Jean, Marcellesi, Florent y Barragué, Borja (2013): Adiós al crecimiento. Vivir bien en un mundo solidario y sostenible. Barcelona: El Viejo Topo.

IMAz, Jose Inazio (2006). Lanaldi murrizketari buruzko eztabaida, 1995-2005. Donostia: Utriusque Vasconiae.

Lindenboim, Javier (2008): «Distribución funcional del ingreso, un tema olvidado que requiere atención", Revista Latinoamericana de Economia , 39 (153), 83-117.

Riechman, Jorge y Recio, Albert (1997): Quien parte y reparte... El debate sobre la reducción del tiempo de trabajo. Barcelona: Icaria.

Rusell, Bertrand (1932): Elogio de la ociosidad. Barcelona: Edhasa, Los libros de Sísifo, 2010.

UGT (2015): Análisis de las horas de trabajo y la jornada laboral en Espala en el periodo 2008-2014, Gabinete Técnico Confederal, 2 de enero, 9 p.

Zubiri, Jon Bernat (2014): «El empleo juvenil como vector de transformación de las sociedades salariales de servicios», Boletín ECOS, 27. 